\title{
Correlation between in vitro and in vivo data on food digestion. What can we predict with static in vitro digestion models?
}

Bohn T. ${ }^{\text {a }}$, Carriere F. ${ }^{\mathrm{b}}$, Day L. ${ }^{\mathrm{c}}$, Deglaire A. ${ }^{\mathrm{d}}$, Egger L. ${ }^{\mathrm{e}}$, Freitas D. ${ }^{\mathrm{f}}$, Golding M. ${ }^{\mathrm{g}}$, Le Feunteun S. ${ }^{\mathrm{f}}$, Macierzanka A. ${ }^{\mathrm{h}}$, Menard O. ${ }^{\mathrm{d}}$, Miralles B. ${ }^{\mathrm{i}}$, Moscovici A. ${ }^{\mathrm{j}}$, Portmann R. ${ }^{\mathrm{e}}$, Recio I. ${ }^{\mathrm{i}}$, Rémond D. ${ }^{\mathrm{k}}$, SantéLhoutelier V. ${ }^{1}$, Wooster T.J. ${ }^{\mathrm{m}}$, Lesmes U. ${ }^{\mathrm{j}}$, Mackie A.R. ${ }^{\mathrm{n}}$, Dupont D. ${ }^{\mathrm{d}^{*}}$

a Luxembourg Institute of Health, Strassen, Luxembourg

b CNRS UMR 7282 EIPL, Marseille, France

c Agresearch, Palmerston North, New Zealand

d INRA UMR 1253 STLO, Rennes, France

e Agroscope, Institute for Food Sciences, Bern, Switzerland

f INRA UMR GMPA 782, Grignon, France

g Massey University, Palmerston North, New Zealand

h Gdansk University of Technology, Gdansk, Poland

i CIAL CSIC-UAM, Madrid, Spain

j Technion - Israel Institute of Technology, Haifa, Israel

k INRA UNH UMR 1019, Theix, France

1 INRA UR 370 QUAPA, Theix, France

m Nestlé Research Centre, Nestec S.A., Lausanne, Switzerland

n University of Leeds, Leeds, UK

*Corresponding author: Dr Didier DUPONT, INRA UMR 1253 STLO, 65, rue de St Brieuc, 35042

Rennes Cedex, France, Tel : +33-2-23-48-53-35, Fax : +33-2-23-48-53-50, e-mail : didier.dupont@inra.fr

\begin{abstract}
During the last decade, there has been a growing interest in understanding food's digestive fate in order to strengthen the possible effects of food on human health. Ideally, food digestion should be studied in vivo on humans but this is not always ethically and financially possible. Therefore, simple in vitro digestion models mimicking the gastrointestinal tract have been proposed as alternatives to in vivo experiments. Thus, it is no surprise that these models are increasingly used by the scientific community, although their various limitations to fully mirror the complexity of the digestive tract. Therefore, the objective of this article was to call upon the collective experiences of scientists involved in Infogest (an international network on food digestion) to review and reflect on the applications of in vitro digestion models, the parameters assessed in such studies and the physiological relevance of the data generated when compared to in vivo data. The authors provide a comprehensive review in vitro and in vivo digestion studies investigating the digestion of macronutrients (i.e. proteins, lipids and carbohydrates) as well as studies of
\end{abstract}




\section{ACCEPTED MANUSCRIPT}

the bioaccessibility and bioavailability of micronutrients and phytochemicals. The main conclusion is that evidences show that despite the simplicity of in vitro models they are often very useful in predicting outcomes of the digestion in vivo. However, this has relies on the complexity of in vitro models and their tuning towards answering specific questions related to human digestion physiology, which leaves a vast room for future studies and improvements. 


\section{ACCEPTED MANUSCRIPT}

\section{Introduction}

There has been a growing interest from the scientific community in getting more information on the effect of food on human health. One strategy to reduce knowledge gaps is to focus on the fate of food during digestion in the gastrointestinal tract (GIT) in order to facilitate the rational design of foods.

The fate of food in the GIT can be studied using several methods or models including static and dynamic in vitro models, various cell and ex-vivo cultures, animals and humans. Recently, such models have also been suggested as valuable tools for investigating the digestion in various populations, such as infants, seniors and IBD patients (REF)[1]. Overall, static in vitro digestion methods are particularly popular because they are easy to use, cheap and do not require specific equipment. However, a huge number of protocols differing in the experimental conditions $(\mathrm{pH}$ and duration of the different steps, amount of digestive enzymes and bile etc) have been proposed making the comparison of results between studies impossible. Recently, an international consensus was reached within the COST Action Infogest (http://www.cost-infogest.eu/) and a protocol published (Minekus et al., 2014) that has since been widely used internationally. Another major drawbacks of static in vitro digestion models is that they are oversimplified and do not take into account the dynamic aspects of the digestive process. Therefore, these models have been used to compare the digestion of related foods under the same conditions (Dupont et al., 2010b), to study the digestion of pure compounds (Benede et al., 2014a; Benede et al., 2014b; Dupont et al., 2010a) or to unravel the interactions between constituents at the molecular level. For instance, using static digestion models, Mandalari et al. demonstrated that interactions were occurring between one of the main milk protein, i.e. $\beta$-lactoglobulin, and phosphatidylcholine released by the stomach wall, protecting the protein from the action of pepsin during the gastric phase (Mandalari et al., 2009).

However, one can question the limits of these static in vitro digestion models to predict other parameters and limit the use of animal or human models. The objective of this opinion paper is to review a range of applications of in vitro digestion models, the parameters that were assessed and the physiological relevance of the data generated when compared to in vivo data. This is the result of a cooperative international effort made by some of the Infogest participants.

\section{Estimation of the digestion of starch}

Starch is the most important digestible polysaccharide in human nutrition usually accounting for 20-50\% of the total energy intake. It is made up of two types of glucose polymers, amylose (15-20\%) and amylopectin (80-85\%), and is predominantly derived from plant seeds such as wheat, maize, rice, oats and rye (Caballero et al., 2012). Given its composition and the predominant role played in the human diet, starch is a major source of glucose that appears at relatively high concentrations in blood circulation during digestion (Butterworth et al., 2011).

Starch digestion is initiated in the oral cavity by salivary $\alpha$-amylase which starts hydrolyzing the glycosidic bonds of amylose and amylopectin (Bornhorst and Singh, 2012). Once the food bolus is swollen, starch hydrolysis by salivary $\alpha$-amylase can continue in the stomach until the $\mathrm{pH}$ lowers sufficiently to inactivate the enzyme (Bornhorst and Singh, 2012; Gropper and Smith, 2013). As no amylase is secreted into the stomach, the last stage of starch digestion occurs in the small intestine where pancreatic $\alpha$-amylase produces maltose, maltotriose and $\alpha$-limit dextrins. These intermediate products are finally hydrolyzed into glucose by specific "brush border enzymes" at the gut wall. Glucose is the final product of starch digestion and is very efficiently absorbed into the bloodstream (Gropper 
and Smith, 2013). The digestive process of starch containing meals can hence easily be followed in vivo by monitoring the rise and subsequent decrease of blood glucose concentrations. Such measurements allow the determination of the postprandial blood glucose response (GR), which is defined as the change in blood glucose concentration in the $2 \mathrm{~h}$ period that follows the start of a meal (ISO, 2010). This type of data is at the origin of a number of metrics used to classify the in vivo digestion of starch and other carbohydrate sources, the most popular of which is the Glycaemic Index (GI) (Dona et al., 2010). Gl is a kinetic parameter first proposed in 1981 (Jenkins et al., 1981). At that time, nutritional recommendations for diabetes were based on food chemical composition only, but concerns that this was not fully representative of physiological effects induced by foods had started being raised. Jenkins et al. (1981) proposed the GI concept as a physiology related metric that could supplement such recommendations. Since then the popularity of $\mathrm{Gl}$ increased as experts stressed the relevance of low $\mathrm{Gl}$ diets to the prevention and management of diabetes and other health conditions including coronary heart disease and possibly obesity (Augustin et al., 2015). Nowadays, GI is defined as the incremental area under the blood GR curve (IAUC) after consumption of a portion of food containing $50 \mathrm{~g}$ (or in some cases $25 \mathrm{~g}$ ) of available carbohydrates expressed as a percentage of the IAUC elicited by a portion of a reference food (white bread or glucose solution) with equivalent amount of available carbohydrate (ISO, 2010). GI is not considered to be a characteristic of the human being but rather a property of the food item itself, specifically, its ability to raise blood glucose (ISO, 2010).

The expensive (Dona et al., 2010) and time-consuming nature (Brand-Miller and Holt, 2004) of the in vivo experiments poses obstacles to the $\mathrm{Gl}$ use, and, along with other factors, these considerations have fueled research on in vitro assays to predict GI values or an equivalent metric (Brand-Miller and Holt, 2004; Dona et al., 2010). Indeed, shortly after proposing the GI concept, Jenkins and coworkers showed that there was a high correlation $(r>0.86)$ between Gls of different foods and their in vitro digestion kinetics, as estimated with a mixture of human saliva and jejunal juice in dialysis bags (Figure 1) (Jenkins et al., 1982). Since then, several research teams have contributed to the development of in vitro static assays with the goal of accurately predicting the glycaemic response of foods. Such assays generally consist in mimicking the different phases of human digestion with commercially available enzymes. Most protocols comprise a simulated gastric phase followed by a small intestinal phase during which samples are collected to analyze the extent of carbohydrate digestion (Bjorck et al., 1994; Englyst et al., 1992; Gibson et al., 2011; Goñi et al., 1997; Monro et al., 2010). In certain cases, gastro-intestinal digestion can be preceded by an in vivo chewing phase (Bjorck et al., 1994; Monro et al., 2010) or an $\underline{i n}$ vitro treatment that often replicates mechanical but not enzymatic oral conditions (Englyst et al., 1992; Gibson et al., 2011). An extensive review of the in vitro protocols available to study starch digestion is outside the scope of the present review but can be found elsewhere (Dona et al., 2010; Woolnough et al., 2008). Here we will focus on a limited number of highly cited methodologies and their correlations with in vivo data.

One of the pioneer in vitro approaches to classify food carbohydrates in a way that reflected their digestion in the gut was performed by Englyst and coworkers (Englyst et al., 1992). The main innovative character of their study was the collection of samples at two distinct time-points of the intestinal phase of digestion (20 $\mathrm{min}$ and $120 \mathrm{~min}$ ) to distinguish rapidly and slowly digestible starch fractions, a characteristic of starchy food that is still extensively used nowadays. Indeed, subsequent research carried out by the same team showed a significant correlation between the proportions of rapidly digestible starch 
of 39 food items and the corresponding GI values obtained from the in vivo literature $(r=0.76)$ (Englyst et al., 1996). The reliability of this method as an indicator of the glycaemic response (GR) to foods was repeatedly confirmed (Araya et al., 2002; Ells et al., 2005; Seal et al., 2003). In the same period, the team of Goñi et al. (1997) was among the firsts to resort to a static in vitro digestion protocol, during which

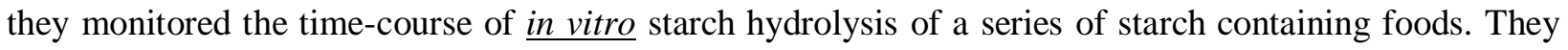
concluded that their 90 min measurement had the best correlation with in vivo GI values $(r=0.91)$ and derived an equation to allow GI values to be predicted from this in vitro approach (Goñi et al., 1997). Other researchers have remarked that although it seems to overestimate the GI, this methodology is sensible enough to reproduce the overall trends observed in vivo (Ferrer-Mairal et al., 2012).

Although some researchers have found a proportional relationship between the quantity of ingested food and the glycaemic response (Englyst et al., 1999), most of in vitro protocols are standardized for fixed amounts of carbohydrate or food. These fixed portions are particularly advantageous for research purposes, yet they have an experimental character and differ from the food quantities that are usually consumed. In order to guide consumer choices based on food or diet effects, it is arguable that one should communicate the glycaemic response in grams per serving of food (Monro et al., 2010). This has raised questions on the ability of $\underline{\text { in vitro }}$ assays to predict glycaemic responses to the varying quantities and compositions of foods that are part of the human diet (Monro et al., 2010), i.e. GR rather than GI. As a matter of course, in vitro experiments overlook the fact that glycaemic responses to foods depend on the balance between blood glucose loading and disposal. As a matter of course, typical blood GRs elicited by carbohydrate-rich foods or meals comprise an initial increase of glucose concentration (loading) and is followed by a decrease to its initial level (disposal) which contrasts with the plateau obtained at the end of in vitro digestion experiments. With the aim of filling this gap, Monro et al. (2010) have proposed to estimate glucose disposal rates from in vivo blood GR data obtained by (Venn et al., 2006) for different glycaemic loads, and to subtract the so-estimated cumulative glucose disposal from the cumulated glucose release that is measured in vitro. This enables the construction of digestion curves that mimic in vivo blood GR curves for a better prediction of the in vivo glycaemic impact of foods (Monro et al., 2010). The correlation of the results obtained with this "in vitro model-assisted" approach with corresponding in vivo data on more than 25 food items proved to be very good both when in vivo data were experimentally obtained as part of the study $\left(r^{2}=0.88\right.$, Figure 2) (Monro et al., 2010) or collected from the literature $\left(r^{2}\right.$ $=0.90$ ) (Monro and Mishra, 2010).

Given the increasing evidences of health benefits associated with a low GI diet, the International Carbohydrate Quality Consortium has very recently reached a scientific consensus defining "an urgent need to communicate information on GI [...] to the general public and health professionals, through channels such as national dietary guidelines, food composition tables and food labels" (Augustin et al., 2015). In parallel, Monro and coworkers concluded that "valid measurement of glycaemic impact of foods may be obtained in vitro" (Monro et al., 2010) and can be applicable for "consumer and industry use" (Monro and Mishra, 2010). Although some researchers have reported discrepancies between in vivo and in vitro results (Berti et al., 2004; Brand-Miller and Holt, 2004; Casiraghi et al., 1992), overall, $\underline{\text { in }}$

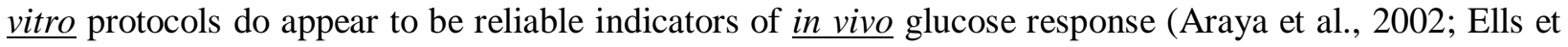
al., 2005; Englyst et al., 1996; Ferrer-Mairal et al., 2012; Goñi et al., 1997; Jenkins et al., 1982; Monro and Mishra, 2010; Monro et al., 2010; Seal et al., 2003). Employing in vitro digestion methods for characterizing the glycaemic impact of foods and labelling purposes is a question that remains to be debated in a larger scientific community. In any case, considering the practicality of $\underline{\text { in vitro }}$ assays, and 
their highly significant correlations with in vivo data, it certainly seems wise to continue optimizing these techniques and take advantage of them in research and early stages of product development.

\section{Assessing protein digestion}

\section{Assessment of protein digestibility}

Evaluating the quality of a dietary protein consists in determining how extensively this protein is digested and absorbed and its amino acids used by the human body. The most frequently used score to express the quality of a protein is the PDCAAS (Protein Digestibility-Corrected AA Score) which takes both the digestibility and the amino acid composition of the protein into account. Although the determination of the amino acid content of a protein is simple nowadays, an accurate and precise determination of its digestibility is still difficult. Digestibility of a protein is a key parameter of its bioavailability (Fuller and Tome, 2005), because it provides some information about the extent of digestion and absorption and the ability of the amino acids to be used. Digestibility (proportion of a protein absorbed from the digestive tract into the bloodstream) has been shown to significantly fluctuate according to the diet, especially between developed and developing countries (Gilani et al., 2005). Protein digestibility is measured indirectly by the quantification of residual nitrogen at the extremity of the digestive tract. Nevertheless, this residual nitrogen includes the non-digested dietary nitrogen but also the endogenous nitrogen. Thus, the quantification of the total nitrogen (exogenous + endogenous) corresponds to the apparent digestibility whereas the estimation of only the exogenous nitrogen corresponds to the true digestibility (Fuller and Tome, 2005). Determination of the true digestibility is more complicated to perform and requires the labelling of the dietary proteins or of the host (to label endogenous proteins). Assessment of ileal digestibility is now recognized as more relevant than determination of fecal digestibility (Darragh and Hodgkinson, 2000; Fuller and Tome, 2005; Moughan, 2003) that can be modulated by the metabolic activity of the intestinal microbiota.

Several groups have tried to determine protein digestibility through in vitro approaches. One of the advantages in using in vitro models to assess digestibility is that endogenous secretions are very limited in these models so that the data generated should be comparable to the true digestibility. In a pioneer work, Saunders et al. showed a good correlation between in vitro digestibility determined on alfalfa protein concentrates with a pepsin-pancreatin or a pepsin-trypsin method and in vivo data collected in a rat trial $\left(\mathrm{r}^{2}=0.914\right)$ (Saunders et al., 1973). Satisfactory results were also obtained on soybean, lupine and rapeseed meal proteins. Indeed, true digestibility assessed on these proteins on rats showed a significant correlation with the degree of hydrolysis $\left(\mathrm{r}^{2}=0.663, \mathrm{p}<0.001\right)$ and nitrogen digestibility $\left(\mathrm{r}^{2}=0.776, \mathrm{p}<0.001\right)$ determined in vitro (Rozan et al., 1997). Finally, Kitabatake and Kinekawa found the same behavior of native and heat-denatured milk whey protein $\beta$-lactoglobulin in vitro and in the stomach of rats (Kitabatake and Kinekawa, 1998). The protein was shown to be fully resistant to proteolysis when native but extensively hydrolyzed when heat-denatured.

However, using an in vitro models, other authors found the same ranking between the in vitro digestibility of different protein sources and in vivo but the values between the 2 approaches remained significantly different (Cho and Kim, 2011). These differences might be explained by an inadequate selection of the parameters of the in vitro digestion model used in this experiment making it physiologically irrelevant.

\section{In vitro/in vivo comparison of milk protein digestion}




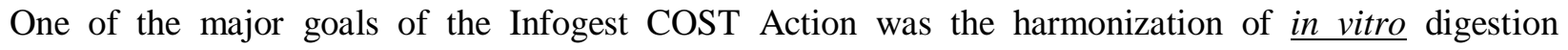
experiments. Towards this end, the consensus static protocol by Minekus et al (Minekus et al., 2014), based on physiological in vivo data was developed. The success of the harmonization was experimentally tested in several inter-laboratory trials, using skim milk powder (SMP) as standardized food matrix. Thus, these efforts not only show the comparability of different digestion protocols, but also serve as a basis for gathering information about milk protein digestion. The participants were asked to digest the SMP first with their in-house method and second with the consensus protocol. Protein decomposition was analyzed at different levels of hydrolysis, from proteins, to peptides, down to free amino acids. Gel electrophoresis, performed with samples after the gastric- and the intestinal phase of in vitro digestion, showed a highly heterogeneous pattern, when the participants applied their in-house methods (data not shown). In contrast to that, the protein patterns of the samples digested with the harmonized protocol were much more homogeneous (Figure 3). Although, in two of these samples, protein hydrolysis was decreased after the gastric phase (Figure 3, lines 6,7), compared to the five other samples (Figure 3, lines 1-5). This difference was explained by a lower pepsin activity, originating from problems with pepsin activity measurement prior to in vitro digestion. However, at the end of the digestion, the protein patterns were very similar and no intact milk proteins were detectable on gels with the harmonized protocol (Figure 3, intestinal phase), whereas some of the samples digested with the in-house methods still had intact $\beta$ lactoglobulin present (data not shown). Analysis of peptides by mass spectrometry showed that the inhouse protocols in general had a lower hydrolysis rate after the gastric phase compared to the harmonized model. Moreover, at the end of the digestion, the peptide patterns were very similar in all the samples digested with the harmonized protocol. The specific digestion patterns for the most abundant milk proteins were visualized by an amino acid counting method, where for the frequency of each amino acid, identified within a specific milk peptide, a color code was attributed and aligned within the protein sequence e.g. $\beta$-casein (Figure 4). This method reveals that the different milk proteins are not randomly but very specifically hydrolyzed during the digestion phases. Considering the five most abundant milk proteins, ( $\beta-$, as1-, $\alpha$ s-, $\kappa$-casein, and $\beta$-lactoglobulin), and using their characteristic digestion data, a Spearman correlation was calculated and the improvement in sample comparability could be confirmed at the peptide level as well in the harmonized protocol (Egger et al., 2016), compared to the in-house methods.

The major conclusion of this work was that the harmonized protocol indeed improved the comparability of experimental results. However, if the in vitro process indeed was comparable to the in vivo situation, was still an open question. To answer this second and important question, an in vivo pig trial was performed, feeding pigs the exact same SMP that was previously digested with the in vitro models. The pigs were fed three times, 6-, 3-, and $1.5 \mathrm{~h}$ prior to sacrifice, respectively with the SMP; the samples were collected at four different zones of the digestive tract. A gastric (stomach)-, duodenal-, upper intestinal(Int 1), and lower intestinal- (Int2) sample, was collected in a total of eight pigs. Protein degradation, generation of peptides and free amino acids were analyzed with the same methods as for the previous inter-laboratory in vitro studies. The similarity of the different investigated digestion models was assessed in a partial least square analysis (PLS), considering the peptide analysis. An average was calculated for each sampling zone (Figure 5, pig- stom, duodenum, Int1, and Int2). The progression in pig in vivo digestion was clearly visible as indicated with the arrow. The samples from the gastric phase of the harmonized protocol all cluster close to the pig stomach sample (Figure 5, light blue) and the samples from the harmonized intestinal phase cluster below the pig Int 2 average (Figure 5, dark blue), indicating that they are possibly to some extend further digested than the pig Int 2 sample. The samples from the 
gastric- or intestinal- phase of the in-house protocols are spread in two groups in the lower part of the PLS analysis, showing that their results are on one hand very variable between each other and more importantly, different from the in vivo samples. In conclusion, it can be stated, that by setting the harmonized protocol in operation, two major goals were achieved. First, the comparability of experimental results between labs and countries was improved and even more importantly, the two endpoints (gastric and intestinal phase) indeed reflect the in vivo pig situation considering the digestion of proteins. Additional work is needed to compare other nutrients in a similar way.

\section{Comparison of bioactive sequences found in vitro and in vivo}

The role of protein digestion in health is undeniable, not only from the nutritional point of view but due to the benefit of released bioactive peptides on health. In this context, it is generally observed that particular stable regions from milk proteins to gastrointestinal hydrolysis are precursors of sequences described as bioactive peptides. This raises the question of the physiological significance of these regions that, in some cases, have deserved to be considered as "food hormones" (Teschemacher et al., 1997). It is also worth considering that the peptide active form is sometimes released only after digestion. An example is fragment 169-175 from $\beta$-casein KVLPVPQ, that possessed a low in vitro ACE-inhibitory activity, but produced a significant antihypertensive effect after its oral administration to spontaneously hypertensive rats. This sequence was shown to lose the Gln at C-terminal end during simulated gastrointestinal digestion, giving rise to KVLPVP, which is presumably the in vivo active form (Maeno et al., 1996).

Some studies have been selected to determine whether bioactive sequences identified after in vitro digestion are illustrative of those found in vivo. In these studies, opioid, antihypertensive and caseinophosphopeptides (CPPs) appear as the best represented cases. Through the reviewed years, the level of evidence and technical advance has increased from finding immunoreactive materials to peptide sequencing.

Bovine $\beta$-casomorphins are opiate-like acting fragments from bovine $\beta$-casein comprising the 60-66 ( $\beta$ casomorphin-7) or C-terminally shortened fragments thereof and were originally isolated from an enzymatic casein digest (Brantl et al., 1979). They show the common $\mathrm{N}$-terminal amino acid sequence YPFP and behave preferentially as $\mu$-type opioid agonists (Brantl et al., 1981). In adult volunteers after ingestion of milk, $\beta$-casomorphin-7 and reduced amounts $\beta$-casomorphin-4 or -6 immunoreactive materials occurred in the duodenal section of the small intestine. The main component of the immunoreactive material was larger than $\beta$-casomorphin-7 and was identified as its precursor (Svedberg et al., 1985). Indeed, this fragment was later isolated from the duodenal chyme of mini-pigs after feeding with the milk protein casein and was referred to as $\beta$-casomorphin-11 which presented four additional amino acids at the C-terminal side (Meisel, 1986). The low amount of this peptide in the duodenum was attributed to rapid brush border degradation and/or high absorption rate of the fragments. More recently, in duodenum of mini-pigs fed gelled skim milk, two additional precursors of $\beta$-casomorphin- $7, \beta$-casein $\mathrm{f}(58-72)$ and $\beta$-casein $\mathrm{f}(59-67)$, were found (Barbe et al., 2014). In human jejunum, upon casein ingestion, $\beta$-casomorphin-7, numerous precursors of this peptide, and the short form, $\beta$-casomorphin-5, were reported (Boutrou et al., 2013).

Jinsmaa and Yoshikawa examined the conditions necessary for the release of $\beta$-casomorphins during $\underline{i n}$ $\underline{\text { vitro }}$ gastrointestinal digestion (Jinsmaa and Yoshikawa, 1999). Pepsin cleaves the $\mathrm{Leu}^{58}$-Val ${ }^{59}$ peptide

bond and leucine aminopeptidase removes the $\mathrm{Val}^{59}$, rendering the $\mathrm{Tyr}$ at the $\mathrm{N}$-terminus. For the 
carboxyl terminus, pancreatic elastase was found responsible for the hydrolysis of the peptide bond Ile $^{66}$ $\mathrm{His}^{67}$ giving rise to $\beta$-casomorphin-7 (YPFPGPI). This means that the inclusion of pancreatic enzymes other than trypsin and chymotrypsin in the in vitro protocol will determine the generation the specific and physiological cleavages releasing $\beta$-casomorphin- 7 from its precursors. $\beta$-casomorphin- 7 has been found upon sequential digestion of infant formulas with pepsin and Corolase $\mathrm{PP} \circledast$ under conditions simulating infant digestion, with gastric pH 3.5 (Hernandez-Ledesma et al., 2004). De Noni, by hydrolysing $\beta$-casein under similar conditions, has also reported its occurrence; the highest amount being recovered when the peptic attack with pepsin was conducted at pH 2.0 (De Noni, 2008). Some precursors included in the $\beta$ casein 57-68 region were found when cheese or milk were digested with pepsin and pancreatin (Hernandez-Ledesma, Quiros et al. 2007; Sanchez-Rivera, Diezhandino et al. 2014) or with human gastrointestinal secretions (Qureshi, Vegarud et al. 2013). Interestingly, an additional hydrolysis step with brush border peptidases released $\beta$-casomorphin-7 (Picariello et al., 2015).

Neocasomorphin-6, $\mathrm{f}(114-119)$ from $\beta$-casein (YPVEPF) was first identified in a gastrointestinal in vitro digest (Jinsmaa and Yoshikawa, 1999) and more recently, it has been reported in human jejunum after milk ingestion (Boutrou et al., 2013). Likewise, this sequence appeared in duodenal effluents of mini-pigs after ingestion of liquid heated milk (Barbe et al., 2014). Neocasomorphin has been also identified after in

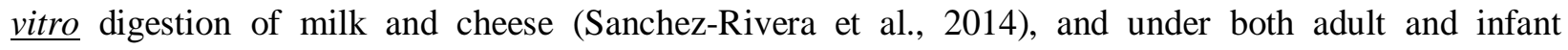
conditions employing physiologically relevant settings (Dupont et al., 2010a; Hernandez-Ledesma et al., 2007). In contrast, other authors have reported the release of a precursor, $\beta$-casein $\mathrm{f}(114-124)$, (Picariello et al., 2010).

Antihypertensive peptides are probably the most numerous bioactive compounds of proteinaceous nature, milk being the main source of peptides with this activity. The complete correspondence between in vitro activity (inhibition of the angiotensin converting enzyme, ACE) and in vivo effect (blood pressure lowering) has not been demonstrated, and it has been attributed to peptide degradation during gastrointestinal digestion or to a poor bioavailability. Hence, the presence of active sequences in digestion effluents marks the first step to know their bioaccessibility and potential absorption (Martinez-Maqueda et al., 2012).

Table 1 shows some antihypertensive peptide sequences that have been reported along the different parts of the intestinal tract in in vivo studies, after consumption of bovine milk or casein in the case of adults, and human milk or infant formula in the case of newborns

The sequences KVLPIPQ and VVPYPQR from human milk, that correspond to the Ile- and Val-replaced antihypertensive peptides $\beta$-casein $\mathrm{f}(169-175)$, KVLPVPQ and $\mathrm{f}(177-183)$, AVPYPQR, respectively, have been identified in the stomach of newborns but also in the undigested milk, which suggested that proteolysis begins during lactation or in the time before feeding (Dallas et al., 2014). In contrast, many unique peptides absent in maternal milk have been found in gastric digests, which suggests that extensive proteolysis also occurs in the term infant stomach. The $\beta$-casein sequence 133-138, LHLPLP, was reported in the jejunum of volunteers ingesting a commercial casein (Boutrou et al., 2013). Precursors of this sequence, $\mathrm{f}(132-140)$ and $\mathrm{f}(130-140)$, are found in the duodenum of pigs upon ingestion of heated milk and acid gels prepared from milk (Barbe et al., 2014). This sequence belongs to a highly conserved $\beta$-casein region in different mammals, resistant to digestion due to the abundance of Pro residues. Numerous related peptides have been found after simulated gastrointestinal digestion of human (Hernandez-Ledesma et al., 2007) and bovine milk proteins (Benede et al., 2014b; Qureshi et al., 2013; 
Sanchez-Rivera et al., 2014). The inclusion of the brush border hydrolases on the digestion model favored the release of different forms with Pro ${ }^{138}$ at the C-terminus (Picariello et al., 2015). From this sequence LHLPLP, various fragments HLPLP, HLPL, LPLP, HLP, LPL and PLP have shown antihypertensive activity (Quiros et al., 2007; Sanchez-Rivera et al., 2016).

In the case of $\alpha_{s 1}$-casein f(143-149), AYFYPEL was found in stomach and duodenum of humans after milk or yogurt ingestion (Chabance et al., 1998), while in duodenum the reported form was $\mathrm{f}(144-149)$, YFYPEL. These peptides have been identified as antihypertensive in a casein hydrolysate (Contreras et al., 2009; Sanchez-Rivera et al., 2014) but recently, its ability to interact with opioid receptors and exert an agonist activity has been described (Fernandez-Tome et al., 2016). Different peptide forms from this region have been found after gastric digestion of milk under dynamic conditions (Sanchez-Rivera et al., 2015) and after in vitro digestion of milk (Dupont et al., 2010b), cheese (Sanchez-Rivera, Diezhandino et al. 2014) and infant formulas (Hernández-Ledesma et al., 2007).

Bovine caseins are also a source of caseino-phosphopeptides (CPPs) that have been proposed to prevent the precipitation of metal ions at alkaline $\mathrm{pH}$ in the distal small intestine (Meisel and FitzGerald, 2003). Interestingly, the phosphorylated regions are relatively resistant to hydrolysis during gastrointestinal digestion. Boutrou et al. showed that in addition to phosphorylation, the presence of bound minerals also prevents CPP from hydrolysis (Boutrou et al., 2010). The analysis of intraluminal digests of Fe- $\beta$-casein $\mathrm{f}(1-25)$ in vascularized rat loop model evidenced that the fragment, which contains the four phosphoserines, $\mathrm{f}(15-25)$, is resistant to proteinases. In the human stomach, phosphorylated fragments from $\beta$-casein 29-41, 33-44, 30-41, 6-17 and 29-40 were identified after milk ingestion. In human duodenum, related forms from these sequences were found (Chabance et al., 1998). In pig duodenum, CPPs from $\beta$-casein together with monophosphorylated sequences from $\alpha_{\mathrm{s}_{1}}$ and $\alpha_{\mathrm{s} 2}$-casein have been reported. However, other phosphorylated regions exhibiting the cluster sequence $S(P) S(P) S(P) E E$ could not be identified under the analysis conditions due to the low ionization capacity of these multiple phosphorylated forms (Barbe et al., 2014). In human jejunum and ileum, related sequences have been found, which implies that phosphopeptides can survive the prolonged intestinal passage in vivo (Boutrou et al., 2013; Meisel et al., 2003).

Phosphopeptide formation and resistance has been followed during simulated gastrointestinal digestion. The use of sequential hydrolysis with pepsin and pancreatin has been shown to release phosphorylated sequences previously reported in vivo, also in infant formula employing suitable conditions (Miquel et al., 2005). Moreover, isolation of the CPP fraction by selective precipitation or $\mathrm{TiO} 2$ chromatography allowed to identify several sequences containing the phosphorylated cluster (Miquel et al., 2006; Picariello et al., 2010). Adt et al. compared the number of sites of phosphorylation of CPPs in nondigested and digested Beaufort cheese samples, and found a decrease in the number of polyphosphorylated peptides (Adt et al., 2011). Still, an important part of the identified peptides contained the characteristic cluster sequence $\mathrm{S}(\mathrm{P}) \mathrm{S}(\mathrm{P}) \mathrm{S}(\mathrm{P}) \mathrm{EE}$. The fact that the analysis was performed on a selective precipitate highlights the importance of this step on the thorough identification of all possible forms.

Altogether, these results denote that in vitro digestion under different conditions is able to release certain gastrointestinal resistant peptides found in human digests. In addition the above examples highlight that not only the enzymes but their concentration, as well as, ion composition and $\mathrm{pH}$ of the digestive juices 
greatly affect the observed results and highpoint the importance of employing parameters deduced from human determinations to obtain physiologically relevant results.

\section{What happens when proteins are cross-linked at the interface of an emulsion?}

Recently, there were extensive studies carried out on how the digestion of interfacial protein in emulsion could be controlled by targeted enzymatic modification of the adsorbed protein layer (Juvonen et al., 2015; Macierzanka et al., 2011; Macierzanka et al., 2012). The main hypothesis was that a change in the pattern of proteolysis might alter colloidal phase behaviour of the emulsion in the stomach and the small intestine, which ultimately might influence both satiety and food intake. Triglyceride oil-in-water emulsions were produced with the milk protein sodium caseinate $(\mathrm{NaCN})$, which was then modified after emulsification by enzymatic crosslinking with microbial transglutaminase (TG). The enzyme was selected because of its common use in food and pharmaceutical applications to strengthen or otherwise modify protein networks (Dickinson, 1997; Fontana et al., 2008). The work on the effect of the TG crosslinking was divided into three parts: (i) development of the emulsification and the crosslinking conditions (Macierzanka et al., 2011), (ii) in vitro static digestion studies, including an interfacial characterisation of changes in the adsorbed protein layer during the digestion (Macierzanka et al., 2012), and (iii) in vivo human studies on postprandial responses (Juvonen et al., 2015).

The in vitro studies (Macierzanka et al., 2012) focused on the effect of enzymatic structuring of $\mathrm{NaCN}$ stabilised emulsion on the pattern of simulated gastro-duodenal digestion of the protein, the interactions with physiologically relevant surfactants (phosphatidylcholine, PC; bile salts, BS), and the resulting microstructural transformations of the emulsion as it passes through different stages of in vitro digestion. By modifying the structure of the $\mathrm{NaCN}$ interfacial layer in emulsions, the aim was to alter the pattern and/or the rate at which the protein was digested under in vitro conditions mimicking physicochemical conditions of the human upper GIT. Significant differences were found between the rates of digestion of $\mathrm{NaCN}$ crosslinked in emulsion (adsorbed protein) and in solution. The crosslinking of interfacial protein delayed proteolysis and prevent the emulsion from destabilising under simulated gastric conditions. In emulsion, the digestion of a population of polypeptides of $M_{r}$ ca. $50-100 \mathrm{kDa}$ was significantly retarded through the gastric digestion. The persistent interfacial polypeptides maintained the original emulsion droplet size and prevented the system from phase separating. In contrast, a rapid pepsinolysis of adsorbed but non-crosslinked $\mathrm{NaCN}$ and its displacement by PC led to emulsion destabilisation. The results suggested that the changes in protein accessibility and structure induced by adsorption to the oil-water interface and TG crosslinking might render the protein less susceptible to hydrolysis in the stomach. After passing from the gastric to the duodenal conditions, the interfacial properties of emulsion droplets were found to be almost exclusively governed by the BS. The interfacial BS also had a dominant role in determining diffusion of emulsion droplets through the small intestine mucus.

In order to determine whether the TG-induced structuring of the interfacial protein layer in emulsion plays a role in controlling postprandial physiological responses, a human clinical trial was carried out using isoenergetic and isovolumic emulsions stabilised with either sodium caseinate (NaCN-E) or TGcrosslinked sodium caseinate (TG-NaCN-E) (Juvonen et al., 2015). Blood samples were collected from the participants at baseline and during the 6-h period postprandially for the determination of serum TAG and plasma non-essential fatty acids (NEFA), cholecystokinin (CCK), glucagon-like peptide 1 (GLP-1), glucose and insulin responses. It was found that the TG structuring of the emulsion interface affected early postprandial metabolic and hormonal responses as reflected by the different postprandial glucose, insulin and CCK profiles. However, the crosslinking did not have a significant effect on the gastric empting (GE) rate or the overall postprandial lipid digestion after the ingestion of the test emulsions. The 


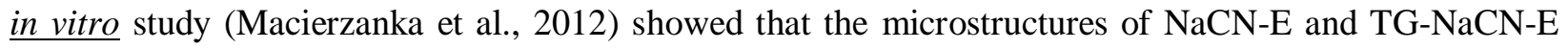
produced with $1 \%(\mathrm{w} / \mathrm{w}) \mathrm{NaCN}$ can be very similar to each other, producing evenly sized oil droplets that are stable to coalescence throughout the course of the in vitro digestion. This could suggest that the GE rate would not be significantly affected by the crosslinking of the interfacial protein. Indeed, the in vivo Magnetic Resonance Imaging showed comparable phase separation for the two emulsions in the stomach, which was probably the reason for the similar GE rates observed (Juvonen et al., 2015). Glucose and insulin blood profiles were lower after consuming TG-NaCN-E than $\mathrm{NaCN}-\mathrm{E}$, which suggested that protein was released from the TG-NaCN-E with a lower rate during the early postprandial phase when compared to the $\mathrm{NaCN}-\mathrm{E}$. Plasma glucose concentration decreased significantly more after the ingestion of TG-NaCN-E than after the ingestion of its non-crosslinked counterpart. As the GE rates were comparable between the test emulsions, the difference observed in the glucose and insulin profiles most probably resulted from the different release and/or absorption rates of the nutrients during the small intestinal phase due to the different initial digestion behaviours of the test emulsions. The postprandial secretion of CCK and GLP-1 was stimulated after consuming the two emulsions, but only the CCK profile differed significantly between the emulsions, showing a stronger increase after the ingestion of TG-NaCN-E than NaCN-E. Those results suggest that even a subtle structural modification of the interfacial protein layer of fat droplets in emulsion can alter the early postprandial profiles of glucose, insulin and CCK through decreased protein digestion without affecting significantly on GE or overall lipid digestion.

\section{Effect of processing on protein digestion - the example of meat}

The effect of cooking on meat protein digestion has been investigated using both $\underline{\text { in vitro }}$ and $\underline{\text { in vivo }}$ approaches (Bax et al., 2013a; Bax et al., 2013b). Although, meat pieces and cooking conditions were not the same, some interesting conclusions can be drawn from the comparison of the obtained results. The $\underline{i n}$ vitro approach consisted of a static digestion miming both gastric and intestinal digestion. For both compartments the kinetics was described and interpreted using a modelling approach allowing the evaluation of the maximal rate of digestion, the time at which it was observed, and the maximal degradation. In vivo, true ileal digestibility of proteins was measured using ${ }^{15} \mathrm{~N}$ labeled meat in cannulated mini-pigs, and digestion rate was evaluated from the kinetics of amino acids appearance in blood. The main data of the 2 studies are presented in Table 2.

Whatever the type of meat (beef, pork or poultry), the muscle composition is essentially driven by contractile proteins (actin and myosin) and sarcoplasmic proteins (myoglobin), that are well conserved across species. The cooking temperatures were also slightly different, but for both meats it can be equated to medium and well-done meat. The comparison of the in vitro and in vivo data thus makes sense. Both approaches showed a decrease in the digestion rate with the more drastic cooking conditions. This is particularly true for pepsin digestion which is probably, with gastric emptying, one of the main determinants of protein digestion rate. The in vitro static model used was not adapted to measure intestinal protein digestibility. For that, instead of measuring OD increase, the measurement of nondigested proteins would have been required. Furthermore, in order to better mimic the in vivo intestinal

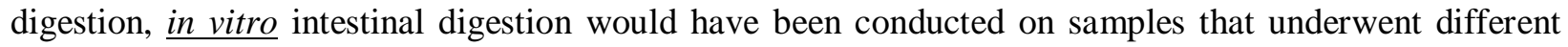
pepsin digestion duration. Nevertheless, in agreement with the true ileal digestibility observed in vivo, the maximal degradation observed $\underline{\text { in vitro }}$ after digestion with pancreatic enzymes was not different according the cooking conditions. The effect of meat cooking on peptides release from proteins during digestion has been investigated using both in vitro and in vivo approaches (Sayd et al., 2016). For 
example, in the case of myoglobin, a total of 34 peptides were identified in vitro and 14 in vivo, with 4 with a same amino acid sequence. Interestingly, the protein presented the same area not degraded when using both approaches (Figure 6).

From this comparison, it can be concluded that the in vitro model properly ranks solid foods according to their digestion rate. It should be noticed that this good correlation was observed with minced meat. As the chewing efficiency greatly affects the in vivo meat protein digestion rate (probably through modification in gastric emptying), the in vitro digestion rate should however be considered as 'potential'. Regarding the overall digestion efficacy, the in vitro static approach proves to be a useful tool to compare the effects of food processing, however it does not provide a digestibility measurement as such.

\section{Bioaccessibility \& bioavailability of micronutrients and phytochemicals}

Simulated in-vitro digestion has, in addition to macronutrients, also been carried out with a large number of micronutrients and phytochemicals, i.e. compounds that may have beneficial health effects but which are not strictly essential. Micronutrients comprise minerals, trace elements and vitamins, while the group of phytochemicals or secondary plant compounds is much larger, including e.g. phytosterols, carotenoids, polyphenols, glucosinolates, triterpenes, and many more. In vitro digestion has been employed for many micronutrients and phytochemicals, including trace elements (iron, zinc), minerals (calcium, magnesium), carotenoids, a range of polyphenols, phytosterols (Moran-Valero et al., 2012), vitamins including B6, B12, E, D, (Etcheverry et al., 2012), and other dietary constituents such as cholesterol (Bohn et al., 2007). In the following section, we will focus on the most prominently examined compounds for which sufficient data is available. For this purpose, the focus will rest on iron as a trace element, carotenoids as vitamin A precursors and the most prevalent lipo-soluble phytochemicals, and polyphenols as the most abundant water-soluble phytochemicals. In addition, their dietary intake has been related to the prevention of micronutrient deficiencies (vitamin A, iron), and chronic disease prevention (carotenoids, polyphenols).

\section{Carotenoids - micronutrients and most abundant lipo-soluble phytochemicals}

Carotenoids as lipophilic constituents differ in their digestion behavior from water-soluble compounds as they require incorporation into mixed micelles, consisting of bile acids, partially digested lipids (mono-, diglycerides), phospholipids, and other lipophilic/amphipathic constituents. Thus, bioaccessibility is equivalent to the amount of carotenoids that are incorporated into mixed micelles in the aqueous phase following oro-gastro-intestinal digestion. For assessment of bioaccessibility, centrifugation and filtration (through $0.2 \mu \mathrm{m}$ or even $0.02 \mu \mathrm{m}$ filters) is typically carried out (Corte-Real et al., 2014), to remove carotenoids trapped in oil or present in the precipitate. Dialysis (through a semi-permeable cellulose membrane) may also be carried out but has shown to produce lower results (Veda et al., 2006). As carotenoids are typically consumed in form of fruits and vegetables, in vitro studies have focused on these food items, which are low in starch, and thus the oral digestion phase has often been left out. It is likewise assumed that carotenoids are mostly absorbed in the small intestine, and that colonic metabolism and uptake is negligible, though very little data is available on this topic (Alminger et al., 2014; Bohn et al., 2015). Additional endpoints that have been determined in vitro include total recovery (Failla et al., 2008), accounting for the presence of non-degraded but not absorbable carotenoids, and carotenoid retention after colonic fermentation (Goni et al., 2006; Kaulmann et al., 2015). Often, digesta have further been investigated for cellular uptake, i.e. coupling in vitro digestion with cellular uptake or transport models of the small intestinal epithelium, typically based on Caco-2 cell models (Biehler et al., 2011a; Corte-Real et 


\section{ACCEPTED MANUSCRIPT}

al., 2016), reflecting intestinal enterocytes, taking into account cellular uptake, intracellular transport, and further sequestration, as well as potential metabolism/cleavage.

As incorporation into micelles is paramount and depends on the presence of bile salts, pancreatic lipase, and lipids during digestion (Bohn, 2008; Borel, 2003), it is important that in vitro methods take these considerations into account, i.e. supplying sufficiently high enzyme and bile salt concentrations (Biehler and Bohn, 2010). Even though additional factors influence the bioavailability of carotenoids, e.g. cellular uptake, transport in the enterocyte, secretion to chylomicrons, re-distribution of carotenoids in lipoproteins (Borel, 2012; Reboul and Borel, 2011), it is believed that bioaccessibility constitutes the most influential factor. Thus, determination of bioaccessibility in vitro should reasonably well reflect bioavailability in vivo.

Bioavailability of carotenoids in vivo is typically determined by analyzing the most recently absorbed carotenoids that appear in the plasma, i.e. in the triacyl-glycerol rich lipoprotein (TRL) fraction, rich in chylomicrons. Mostly, the area-under-time-curve (AUC, for 10-12 hours) above baseline (before test meal intake) is determined as a marker for bioavailability, which can be translated into fractional absorption (Bohn et al., 2013; O'Neill and Thurnham, 1998).

Only a few studies have attempted to compare results from in vitro to $\underline{\text { in vivo }}$ studies, with generally promising conclusions, i.e. a reasonable correlation between the two. Reboul et al. (2006) compared fractional incorporation into micelles of alpha-and beta-carotene as well as of lutein and lycopene from different test meals following in vitro digestion to earlier conducted in vivo incorporation into micelles from similar test meals, obtained by the same group (Tyssandier et al., 2003). In general, a high correlation $(\mathrm{R}=0.90, \mathrm{P}=0.038)$ was encountered, suggesting that the bioaccessibility results in vitro in tendency reflect in vivo bioaccessibililty, pointing out that indeed intestinal solubility is a crucial parameter for carotenoid bioavailability (Figure 7). Furthermore, the authors compared their own bioaccessibility results for lycopene, beta-carotene and lutein with bioavailability results (TRL-AUC values) from other authors, employing similar test meals, finding a high overall correlation of $\mathrm{R}=0.98$ $(\mathrm{P}<0.001$, Figure 8), with a better correlation for beta-carotene $(\mathrm{R}=0.998)$ compared to lycopene $(\mathrm{R}=0.54)$, perhaps due to the lower availability of lycopene in general. However, it should also be noted that up to 8-fold differences occurred between bioavailability and bioaccessibility, and that individual values can significantly deviate from an average correlation. These differences may be due to factors related to absorption and further transport, which can greatly vary between individuals. Similarly, in a study by Alminger et al. (2012), bioaccessibility of lycopene and beta-carotene from soups containing tomato, broccoli and carrots, was compared to human bioavailability (determined via plasma concentrations after several weeks of consumption), and found generally comparable results for betacarotene $(\mathrm{R}=0.93)$ and 5-cis lycopene $(\mathrm{R}=0.87)$ for various types of soups. Interestingly, cellular uptake equally well correlated with in vivo data. Recent studies have shown that inter-individual absorption of lutein (Borel et al., 2014), lycopene (Borel et al., 2015b) and beta-carotene (Borel et al., 2015a) depended also on the presence of single nucleotide polymorphisms (SNPs), related e.g. to carotenoid transporters or cleavage enzymes (Borel, 2012), which are not accounted for by $\underline{\text { in vitro }}$ studies.

As not all of the bioaccessible fraction may be taken up and further transported and absorbed by intestinal lining, bioaccessibility, at least for the better soluble xanthophylls, may tend to overestimate bioavailability, as also seen in dynamic models (Van Loo-Bouwman et al., 2014; Van Loo-Bouwman et al., 2010). For example, Unlu et al. (2005) reported bioavailability of lutein from spinach/mixed salad 
(when served with sufficient amounts of fat) of $28 \%$ while in vitro bioaccessibility from another type of spinach was reported as 58\% (Biehler et al., 2011b). For lycopene from tomato juice, human bioavailability was calculated as $3.1 \%$ in one trial (Bohn et al., 2013) while bioaccessibiliy was in a similar range (2.9\% et al., Corte-Real and Bohn, unpublished), though again, based on different juices.

\section{Polyphenols - water soluble phytochemicals}

Unlike carotenoids, most polyphenols (with few exceptions such as resveratrol and curcumin), are reasonably well water-soluble. Thus, their bioaccessibility does not rely on micellization, but rather on release from the matrix and their staying in solution in the aqueous phase, as some polyphenols may be complexed with proteins (digestion enzymes) or minerals, and may precipitate (Bohn, 2014).

Upon matrix release, polyphenols are partly taken up by the epithelium in the small and/or large intestine. In order to be absorbed, it appears (apart for some anthocyanins) that glucosides must be cleaved to liberate the respective aglycons (by e.g. cytosolic beta-glucosidase, phlorizin-hydrolase of the brushborder, or, to a lesser extent, by the low $\mathrm{pH}$ in the stomach). These aglycons can then be taken up via passive diffusion or via transporters. Many compounds are however re-excreted into the gut via transporters, or are glucuronidated/sulfated, and can be further metabolized in other tissues (e.g. the liver). Thus, compared to their native compounds, they may undergo substantial metabolism, depending largely on the polyphenol type.

Following in vitro digestion, bioaccessibility is either determined following centrifugation (Mandalari et al., 2013) centrifugation/filtration (Kaulmann et al., 2015), or, alternatively, following diffusion through semipermeable membranes (dialysis), with e.g. 10,000-12,000 Da cut-offs (Bouayed et al., 2012; Bouayed et al., 2011; Gil-Izquierdo et al., 2002), simulating that only soluble, small molecules can be taken up by the epithelium. The differences between these methods may be considerable, and recoveries appear lowest for dialysis (Bouayed et al., 2012). In contrast, in vivo bioavailability of polyphenols may either be compared by their (or their metabolites) urinary excretion (for water soluble polyphenols such as isoflavones, (Bohn et al., 2013), shown to vary between 0.3-43\% (Manach et al., 2005), by their plasma appearance (Guo et al., 2014) over time (AUC), or via the feacal balance method (reflecting absorption) when colonic metabolism can be neglected, such as in ileostomists (Erk et al., 2014). The AUC following a single dose application is supposed to best reflect bioavailability of polyphenols (Carbonell-Capella et al., 2014).

Thus, factors effecting polyphenol matrix release are crucial and must be mimicked in vitro, possibly including mastication, mechanical movements during gastric phase, $\mathrm{pH}$ (that could aid in liberation via hydrolyzing reactions), influence of enzymes aiding in the degradation of the matrix and in polyphenol release. For polyphenols however, there are at least 3 major concerns regarding in vitro digestion that clearly limit the predictability of bioavailability. These are:

1. The absence of a colonic fermentation step for most in vitro models, where polyphenols are heavily metabolized. Many polyphenols reach the colon, where the microbiota can lead to additional reactions, including ring fission, deglycosylation, hydrolysis, deglucuronidation, and demethylation (Alminger et al., 2014; Bohn et al., 2015), resulting in products that may be absorbable in the colon.

2. Many polyphenols are bound in the non-extractable fraction (NEPP) that may not be released in the gastric phase/small intestine (Bohn, 2014), but perhaps in the colon, such as phenolic acids. A 
large proportion of polyphenols is covalently bound, and are not extractable by chemical means (Arranz et al., 2010; Perez-Jimenez et al., 2013) or released in the small intestine. This NEPP fraction may exceed the extractable fraction.

3. Bioavailability of polyphenols is altered by transporters in the gut, phase I/II metabolism reactions, and rapid turnover/excretion. For example, polyphenols may interact in a way that favours cellular uptake due to blocking certain efflux transporters into the gut lumen, or may override certain phase I/II metabolizing enzymes (Bohn, 2014), processes that are typically not studied in vitro, unless in vitro digestion is coupled to cellular models (Andre et al., 2015; Kaulmann et al., 2015), though detection problems may then become a concern.

These factors impede estimating polyphenol availability by in vitro methods compared to e.g. less heavily metabolized compounds (e.g. carotenoids). Nevertheless, a few studies have compared their in vitro bioaccessibility with in vivo human trials. Brown et al. investigated the polyphenol composition of lingonberries following both in vitro (including faecal fermentation) and in vivo digestion in ileostomists (Brown et al., 2014). Certain differences in polyphenol composition were found between the ileal efflux and the bioaccessible fraction in vitro, and were explained by the absence of brush-border enzymes, e.g. phlorizin-hydrolase, but also cytosolic beta-glucosidase (cleaving sugar-moieties), from in vitro model.

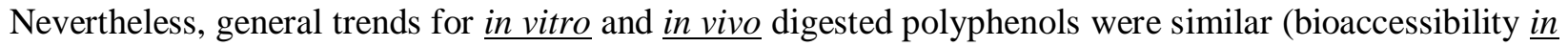
vitro $28 \%$ and $49 \%$ in vivo). The results emphasize that the correlation between in vitro digestion with faecal fermentation and colonic bioaccessibility in vivo (ileostomist model) can be reasonable. Vetrani et

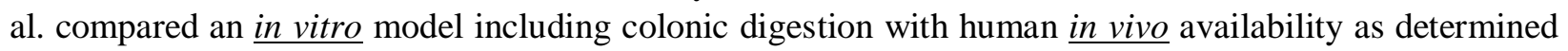
via urinary excretion (Vetrani et al., 2016), based on over 70 subjects consuming a polyphenol rich diet over 8 weeks. A significant though low correlation of $\mathrm{R}=0.280(\mathrm{P}=0.04)$ was found for 15 metabolites, suggesting that when combined with colonic fermentation, the model may predict polyphenol uptake and excretion to a certain extent.

For compounds that are unstable (but absorbable) during the upper stages of digestion, in vitro models may more accurately predict bioaccessibility. For example, anthocyanin (as parent compounds) urinary excretion has been reported to be below 5.1\% (range 0.004 - 5.1\%, (Kalt et al., 2014; Manach et al., 2005), while in vitro studies have suggested a bioaccessibility between zero in apples (Bouayed et al., 2011) to $4.6 \%$ from mulberries (Liang et al., 2012). For compounds that are absorbed to a high extent in the small intestine, such as isoflavones, it is also worth to compare in vitro with in vivo results. While most in vitro studies of soy isoflavonoids suggest a higher bioaccessibility of the glucosides (due to their higher water solubility), between $80-100 \%$ (Table 3), aglycons (more apolar, perhaps requiring micellarization) range lower in bioaccessibility, approx. 30-60\%. However, in vivo differences between aglycons and glucosides appear negligible (Nielsen and Williamson, 2007; Zubik and Meydani, 2003). It is assumed that glucosides require cleavage into agylcons prior to uptake, reducing the initial advantage of higher solubility. However, bioaccessibility may well predict relative absorption between various

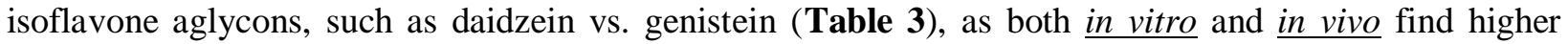
potential uptake/absorption of the more polar daidzein vs. genistein, when measured by urine excretion or by fractional absorption (faecal balance method). When measured as AUC in plasma however (a more accurate measure of bioavailability, accounting for uptake, biodistribution and excretion), genistein showed higher bioavailability (Setchell et al., 2003), as daidzein more rapidly is distributed into other tissues (higher volume of distribution $\left(\mathrm{V}_{\mathrm{D}}\right)$ ). It is therefore important to clearly define "bioavailability" noting that the latter is different from absorption or excretion. 
As measuring all individual polyphenols may be less practical, some in vitro methods have investigated total polyphenol recovery following in vitro digestion by the Folin-Ciocalteu method (Table 3), though not being specific for polyphenols (also detecting e.g. reducing sugars). When compared to in vivo bioavailability (either estimated by urine appearance or by plasma AUC), results appear to be in the same range of availability, though it is hard to compare the various test meals and various measures of bioavailability. Unfortunately, the Folin-Ciocalteu method is not applicable in vivo, where too many other factors influence anti-oxidant capacity of plasma.

\section{Trace elements - example iron}

One of the first digestion methods that has latterly been transferred to many other applications was described by Miller et al. (1981), set up originally to study iron bioaccessibility. Unlike organic micronutrients (vitamins) and phytochemcials, minerals do not undergo significant metabolism during digestion. However, oxidation/reduction may take place that can influence mineral bioavailability, and especially divalent minerals may undergo complexation during digestion, impinging on their availability. In order to be available, minerals/trace elements are believed to require solubilization (except perhaps, in the form of nanoparticles), which depends on the $\mathrm{pH}$, concentration of the mineral, and the presence of other complexing agents. For example, $\mathrm{Fe}^{2+}$ may be oxidized into the non-absorbable $\mathrm{Fe}^{3+}$, or it may be complexed by organic acids such as phytic acid, oxalic acid or polyphenols, greatly reducing availability, similarly for other minerals (Bohn et al., 2004a; Bohn et al., 2004b; Hurrell, 2007). Higher pH generally limits the availability of divalent minerals/trance elements, as solubility decreases with higher $\mathrm{pH}(>7)$, as insoluble oxides/hydroxides may form.

As for most minerals, iron is believed to be primarily absorbed in the upper intestine, though also colonic absorption, especially at lower $\mathrm{pH}$ (improved solubility), such as following fermentation of probiotic fiber, cannot be excluded (Scholz-Ahrens et al., 2007). An additional consideration is that for certain minerals there may be several non-exchangeable sources, termed "pools", with different availability, such as for iron, zinc, and selenium. There are two main dietary sources of iron which do not mix during digestion, i.e. iron in hemoglobin in meat/fish and products (heme-iron), and non-heme iron from plant sources, which are absorbed in a different way, with heme-iron having a 5-10 times higher bioavailability. This is because iron bound to heme is taken up as an entire peptide (possibly via endocytosis), while nonheme iron is absorbed in the intestine as $\mathrm{Fe}^{2+}$ via divalent metal ion transporter 1 (Fuqua et al., 2012), susceptible to oxidation and complexation. As iron, unlike other minerals, where bioavailability may be best determined via plasma measurements, is mostly incorporated into erythrocytes (hemoglobin), measuring iron in red blood cells, such as several weeks following the intake of isotopically labelled iron, is the gold standard for iron absorption studies. However serum appearance curves have shown to correlate well with erythrocyte incorporation (Conway et al., 2006). In vitro, many studies have either focused on the bioaccessible fraction as measured via dialysis, to exclude iron bound/complexed to macromolecules (proteins, high molecular weight polyphenols) and not being bioavailable (Miller et al., 1981), or following prolonged centrifugation and filtration (Kulkarni et al., 2007), resulting in generally higher values than dialysis. As heme-iron absorption cannot be studied in vitro, in vitro digestion does not allow to compare between heme-iron and non-heme iron availability.

Many studies have compared in vitro available iron with bioavailable iron in human trials. For example, iron availability has been studied from different iron salts with and without the addition of sodium EDTA (ethylene diamine tetra-acetic acid) from corn masa flour tortillas. A high correlation was found between 


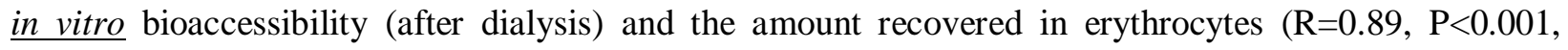
Figure 9). However, bioavailability was higher (by a factor 2) than bioaccessibility (Walter et al., 2003). It appears that for other minerals, which are usually absorbed to a higher degree, such as $\mathrm{Mg}$ and $\mathrm{Ca}$ (absorption approx. 20-40\%), bioaccessibility and bioavailability values show less discrepancy. However, comparable results were obtained when correlating in vitro results by Aragon et al. (2012) with those of Davidsson et al. (2002), contrasting in vitro dialysability of various iron salts with and without EDTA, and erythrocyte incorporation of stable iron labelled test meals with the same iron compounds ( $\mathrm{n}=6$, $\mathrm{R}=0.80$ ). In another comparison, various concentrations of ascorbic acid were added to test meals to investigate the effect on iron absorption. When comparing results obtained from this study, i.e. dialyzable iron fraction (Aragón et al., 2012) with earlier results from a similar study in vivo (erythrocyte incorporation (Cook and Monsen, 1977), a similar high correlation was obtained ( $\mathrm{R}=0.98$ ). In addition to iron salts, also different food items have been compared. Sandberg et al. (2005) presented data from various test meals, comparing in vitro solubility with human absorption studies (erythrocyte incorporation), and found a very high correlation $(\mathrm{R}=0.97)$, though with solubility being approx. twice as high as iron absorption (Figure 9).

General limitations of the dialysis technique are that large molecules such as heme-iron or ferritin would be bioavailable, but not dialyzable, while some smaller compounds that are dialyzable such as phenolic complexes or complexes with organic acids can diffuse through the semipermeable membrane, but would generally not be bioavailable. As transporters may play important roles, especially between different mineral pools (e.g. heme iron and non-heme iron), predictability across those different forms is not possible by in vitro techniques. Some of these limitations may be overcome by coupling in vitro digestion with other techniques, i.e. based on cell culture. Correlations were high when comparing cellular uptake (a Caco-2 based model) following in vitro digestion and human bioavailability (erythrocyte uptake) following the addition of ascorbic acid or tannic acid (a polyphenol) to a semi-synthetic meal ( $\mathrm{R}=0.934$, $\mathrm{P}=0.012$ and $\mathrm{R}=0.927, \mathrm{P}=0.007$, respectively), though iron uptake was (as mostly done for cellular studies) determined via ferritin expression (Yun et al., 2004).

In summary, while the tendency, that is the direction of bioavailability (higher, lower, equally well) appears to be generally predictable by methods incorporating in vitro digestion, this does mostly not predict the magnitude of bioavailability in humans, as too many processes, namely transport, phase I/II metabolism, colonic changes (especially for polyphenols), biodistribution and (renal) excretion affect bioavailability of micronutrients and phytochemicals in many different manners, which cannot be predicted by this method. A more accurate method is the coupling of in vitro digestion to cell models of the epithelium, such as Caco-2 cells, which may simulate, to a certain extent, transport and secretion to the basolateral side, as well as model some aspects of further metabolism. It should further be noted that though bioaccessibility often appears to be reasonably correlated with absorption (and urinary excretion), this is not necessarily true for bioavailability as determined via the AUC in plasma, which depends on further biodistribution. Generally, bioaccessibility tends to overestimate bioavailability, due to the involvement of limiting transporters in vivo. Despite these limitations, in vitro models have developed into very useful tools for hypothesis building and investigating a large number of potential influential factors governing digestion of micronutrients and phytochemicals.

\section{Lipid digestion}


The use of in vitro models in the study of food materials during digestion invariably requires the progression of findings from simulation to human studies. Ideally, observations made as part of human trials should be able to be correlated with findings from in vitro analysis, thus demonstrating the physiological relevance of the model. A particular challenge with this approach, beyond ensuring that any model provides sufficient representation of human digestive physiology, is the identification and characterisation of complementary markers across both in vitro and in vivo analysis that can be used to establish particular correlations between simulated and human studies. The uptake of dietary lipids involves luminal hydrolysis of triglycerides by gastric and intestinal lipases followed by absorption across the epithelium and re-assimilation into triglycerides in the enterocytes. Biomarkers most commonly used to follow lipid digestion are fatty acid release (in vitro) and triglyceride appearance in blood, plasma-TAG (in vivo). Good in vitro/ in vivo correlations are thus often impaired by the fact that in vitro data mostly reflect the intraluminal step of lipid digestion while in vivo data reflect the overall process of digestion and intestinal absorption without any information on rate limiting steps. A first challenge is therefore to find in vitro and in vivo data that reflect similar processes. Another challenge when creating in vitro models to assess lipolysis is ensuring accurate representation of both the biochemistry and biophysics of the gastrointestinal tract.

When considering replication of the biochemistry of lipolysis, good in vivo-in vitro correlations were obtained during the gastrointestinal lipolysis of complete test meals and $\mathrm{O} / \mathrm{W}$ emulsions, using a two-step static in vitro digestion model. This model was initially developed based on in vivo data recorded during the digestion of a liquid test meal in healthy volunteers and the arbitrary choice of conditions existing in the stomach and small intestine at 50\% gastric emptying (Carriere et al., 2000; Carrière et al., 2001). The mean $\mathrm{pH}$ values of 5.5 and 6.25 measured in gastric and duodenal contents, respectively, were chosen for the gastric and duodenal steps of in vitro digestion. Gastric lipase concentration was $17 \mu \mathrm{g} / \mathrm{mL}(20 \mathrm{U} / \mathrm{mL}$ on tributyrin; (Gargouri et al., 1986)) for the gastric step and the solution mimicking human gastric juice was prepared using either purified human gastric lipase (HGL), recombinant dog gastric lipase (rDGL) or a rabbit gastric extract (RGE) containing rabbit gastric lipase (RGL) because these enzymes have similar lipase activity and specificity. For the duodenal step, a 1.7-fold dilution of gastric mixture was applied, resulting in a gastric lipase concentration of $10 \mu \mathrm{g} / \mathrm{mL}$, while pancreatic lipase and bile salt concentrations were set at $250 \mu \mathrm{g} / \mathrm{mL}(2,000 \mathrm{U} / \mathrm{mL}$ on tributyrin; (Carrière et al., 1993)) and $4 \mathrm{mM}$, respectively, using either purified human pancreatic lipase (HPL) or porcine pancreatic extracts (PPE) as a source of pancreatic lipase, and either human or bovine bile (Sigma B3883) as a source of bile salts. The choice of incubation times (30 $\mathrm{min}$ for the gastric step $+60 \mathrm{~min}$ for the duodenal step) was also arbitrary.

Nevertheless, the choice of these conditions allowed the measurement of gastric $(t=30 \mathrm{~min})$ and gastric + duodenal ( $\mathrm{t}=90 \mathrm{~min}$ ) lipolysis levels ( $\%$ of fatty acids released from triglycerides) that were in the same range as the lipolysis levels measured in vivo during the whole meal digestion in the stomach and duodenum (Table 4). In this later case, gastric lipolysis was deduced from the total output of lipolysis products passing through the pylorus, while gastric + duodenal lipolysis was deduced from the output of lipolysis products collected by continuous aspiration at the Angle of Treitz (junction between duodenum and jejunum). Both in vivo and in vitro studies revealed a faster lipolysis of the liquid test meal compared to the solid-liquid test meal (Table 4). This was attributed to the fact that triglycerides in the homogenized liquid test meal were finely emulsified with lecithin, thus providing a good and accessible substrate for lipases, while triglycerides in the solid-liquid meal had various origins and reduced accessibilities (butter, cooking oil, meat fat). Further experiments with the lipase inhibitor Orlistat 
confirmed that the two-step static in vitro digestion model was predictive of $\underline{i n}$ vivo gastric and duodenal lipolysis levels, as well as of undigested fat excretion in feces when gastrointestinal lipolysis was impaired (Carrière et al., 2001).

The same two-step static in vitro digestion model was used to study the effects of various emulsifiers on the bioavailability of $\alpha$-linolenic acid (ALA) from flaxseed oil, in combination with an in vivo study of ALA lymphatic secretion in rats (Couedelo et al., 2015). In vitro data showed that the emulsification of flaxseed oil with soya lecithin led to a higher level of gastric lipolysis compared to the emulsification with sodium caseinate (Figure 10; Table 4). Similarly, duodenal lipolysis of flaxseed oil was also higher with lecithin than with caseinate (Figure 10; Table 4). The in vivo data obtained with the same emulsions and lymph collection in rats showed significant changes $(\mathrm{p}<0.05)$ in the kinetics and overall absorption (AUC) of ALA over the 6 hours post-feeding. The resulting lymphatic secretion of ALA was 3-fold higher with soya lecithin $\left(\mathrm{C}_{\max }=24 \pm 3 \mathrm{mg} / \mathrm{mL}\right.$; $\left.A U C=60 \pm 32 \mathrm{mg} / \mathrm{ml} \times \mathrm{h}\right)$ than with caseinate $\left(\mathrm{C}_{\max }=7 \pm 4 \mathrm{mg} / \mathrm{mL}\right.$; $\mathrm{AUC}=24 \pm 14 \mathrm{mg} / \mathrm{ml} \times \mathrm{h}$ ). In addition, the synthesized chylomicrons were notably larger and more numerous with soya lecithin whereas they were smaller in the presence of caseinate. These results suggest that the intestinal bioavailability of ALA is increased by the emulsification of flaxseed oil with soya lecithin via an improved lipolysis, favouring the intestinal absorption of ALA and the secretion of many large chylomicrons in lymph. In vitro lipolysis rate of flaxseed emulsions therefore appears as predictive of intestinal absorption rate, probably because lipolysis is the limiting step in the overall bioavailability of fatty acids. Using the same two-step static in vitro digestion model, similar differences in the effects of lecithin and caseinate on lipolysis rates were observed with rapeseed oil and milk fat olein emulsions (Table 4; (Vors et al., 2012)).

Since lipid digestion is an interfacial process its speed is controlled by droplet surface area (Benzonana and Desnuelle, 1965) and the nature of the surfactants which can impair enzyme accessibility at the surface (Delorme et al., 2011), hence the structural transformations that an emulsion might undergo as a result of gastrointestinal biophysical processes need to be considered during in vitro testing. This consideration is highlighted in a series of studies progressing from in vitro to in vivo undertaken on "gastric structured" emulsions (Day et al., 2014; Golding et al., 2011; Keogh et al., 2011; Steingoetter et al., 2015; Wooster et al., 2014). The study design was based on the hypothesis that the rate and possibly extent of lipid uptake could be controlled by manipulating the surface area of fat to which digestive lipases could adsorb (such that lower surface areas would present fewer biding sites, leading to a reduction in the relative rate of digestion). To test this hypothesis, model emulsions were formulated to undergo a number of structural transitions when exposed to the biophysical conditions in the stomach (noting that all emulsion were initially stable and had comparable particle size distributions and viscosities). Dependent on composition, emulsions could be tailored to remain stable, flocculate, coalesce, partially coalesce (due to the presence of solid fat within the droplets at $37^{\circ} \mathrm{C}$ ), and fully break upon prolonged exposure to gastric environment (Figure 11).

The study design initially involved the use of static in vitro gastric and small intestinal models to assess microstructural changes and extent of lipid digestion. Incubation of emulsion samples within the in vitro models, coupled with confocal microscopy, provided evidence of how conditions of $\mathrm{pH}$, presence of enzymes and bile, and the application of shear at physiological temperatures impacted on emulsion structure during simulated digestion (Golding et al., 2011). In this respect, the static in vitro model was able to demonstrate the responsiveness of emulsion structures to particular physiological variables, enabling high throughput determination of structure dynamics based on iterative formulation design 
(Figure 11a). The in vitro model also enabled the extent of lipolysis to be measured for these emulsions during simulated small intestinal digestion, using a $\mathrm{pH}$-stat methodology to determine the rate of fatty acid synthesis arising from triglyceride hydrolysis. This approach was able to confirm that low surface area emulsions that had undergone coalescence, partial coalescence or breaking during gastric incubation were significantly more slowly hydrolyzed compared to structurally stable or flocculated emulsions that retained high surface area.

Based on in vitro findings, selected emulsion systems were studied in vivo using conventional dietary interventions and studies using MRI (Golding et al., 2011; Keogh et al., 2011; Steingoetter et al., 2015). Upon consumption, the different emulsions were isocaloric, isoviscous and had the same initial droplet size distribution, but were again designed to undergo particular gastric structuring mechanisms based on earlier in vitro findings. Identification and development of complementary measurement techniques between in vitro and in vivo study methodologies was an important consideration in allowing correlations (of both structural dynamics and digestive properties) between the two approaches to be established. In the case of emulsions undergoing dynamic gastric structuring, information on gastric structure (MRI Imaging), emptying (Paracetamol absorption \& MRI stomach volume) and triglyceride absorption (Plasma-TAG) were key biomarkers of interest.

Variations in plasma-TAG onset time, peak and area under the curve provided information on the relative rate and extent of fat digestion taking place, which could in turn be correlated to rate of fatty acid release during in vitro digestion (Figure 11b). Intralipid was used as a (stable, high surface area) control emulsion for these studies, thereby providing initial comparison between $\underline{\text { in vitro }}$ and in vivo measurements. Comparison of a samples plasma-TAG profile to Intralipids could accordingly be used as an indicator of whether changes to in vitro fatty acid release arising from emulsion structuring were similarly represented by changes in vivo. In this respect, specific (and reproducible) in vitro-in vivo correlations were able to be established. Notably, partially coalescing emulsions, for which in vitro fatty acid release was found to be greatly diminished when compared to Intralipid, showed a markedly suppressed plasma-TAG response when compared to the same control. However, a poor in vitro - in vivo correlation was found when comparing emulsions that broke under gastric conditions. In vitro digestion experiments predicted a slow intestinal uptake, however in vivo plasma-TAG curves showed a delayed but fast intestinal lipid update. It was proposed (and later confirmed by MRI) that the main source of this discrepancy arose from delayed gastric fat emptying with concurrent re-dispersion during passage through the antrum-pylorus (Steingoetter et al., 2015). This highlights the widely held belief that a key limitation of static in vitro models is accurate representation of digestion biophysics (gastric mixing and emptying), such limitations have vastly been improved in the TNO intestinal model and IFR Model Gut dynamic digestion models (Minekus et al., 1999; Wickham and Faulks, 2007).

\section{General conclusion}

Food digestion is a complex series of dynamic processes that involve the transit of food through different compartments of the gastrointestinal tract, the exposure to time-dependent and loci-dependent events as well as intricate interactions with the epithelium and immune system. These include events such as evolution of $\mathrm{pH}$ in the different compartments, dynamics of gastric emptying, intestinal motility, production and release of digestive enzymes and bile as well as other events, such as degradation by brush border enzymes on the membrane of gut epithelia. Therefore, simulating digestion with rather basic static 


\section{ACCEPTED MANUSCRIPT}

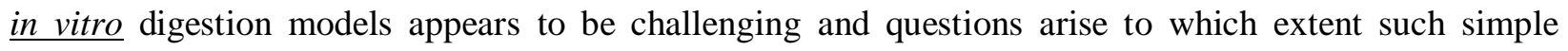

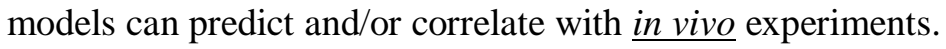

When considering macronutreint digestion, detailed understanding of digestion biochemistry has allowed in vitro models to become a relatively good predictor of in vivo behavior. This is especially true when considering simple/stable emulsions, simple protein solutions or starch. In the case of simple emulsions the extent of gastric and/or gastric + duodenal lipolysis measured in vitro were in the same range as the lipolysis levels measured in vivo. For protein digestion, in vitro models appear as potential predictor of true digestibility or, at least, are useful to rank different protein sources according to their digestibility. Similar patterns of bioactive peptides have been observed when comparing in vitro and in vivo models, thus in vitro models could be used to predict the release of bioactive sequences in the gastrointestinal tract. However, more work is needed to assess whether in vitro models could evaluate concentrations of bioactive sequences in the lumen. Similarly, there are exemplary studies by various groups demonstrating the excellent correlation between in vitro and in vivo data for assessing the digestion of starch. However, in the case of digestion of complex or realistic foods whose structure changes as a result of interaction with the biophysics of the digestive environment, there are moderately good in vitro-in vivo correlations. Such in vitro-in vivo correlations can be hampered by various factors which are ill-represented in static in

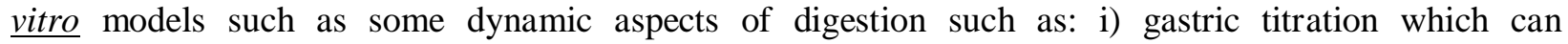
rehomogenise emulsion structures and/or ii) rate of gastric empting/secretions which affect the extent of microstructural changes and lipolysis kinetics.

When considering the digestion of micronutrients, nutraceuticals and food bioactives, our understanding does not go as far as it does for macronutrients. For carotenoids, in vitro bioaccessibility reasonably predicts in vivo bioavailability, especially on the greater average. While absolute bioavailability is harder to predict, the relative availability, e.g. when comparing availability of carotenoids from 2 test meals, appears to be quite well predictable. The case of polyphenols is rather different, as their bio-efficacy may involve intricate pathways involving the gut microbiome as well. If fecal fermentation is excluded from the model for predicting the bioavailability of individual compounds, results do not appear meaningful, except for compounds mostly absorbed in the upper part of the intestine such as for certain flavonoids. When estimating global bioavailability from a product, i.e. the sum of total phenolics, without focusing on individual compounds, the in vitro method appears to perform reasonably well, when compared to

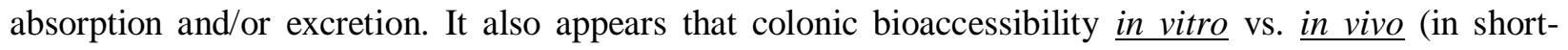
bowel subjects) is well correlated, though differences due to brush-border enzyme activities exist.

Nevertheless, this exhaustive review of the recent knowledge acquired on the ability of static in vitro digestion models to mimic the in vivo reality clearly shows that static models can be physiologically relevant in some cases. There are indeed strong evidences that in vitro protocols do appear to be reliable indicators of the glucose response in vivo and could even be of great interest for the design of new foods with specific carbohydrate digestion rates. Furthermore, when in vitro digestion is coupled to faecal

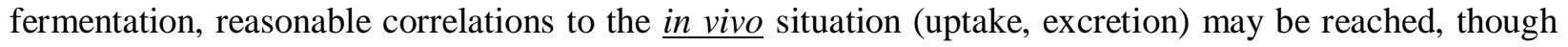
more data is required in this respect.

Therefore, although in vitro static models are over-simplistic and do not reproduce all the dynamic aspects of the gastrointestinal tract, they are increasingly useful in predicting in vivo digestion in some cases. Thus, they offer food and health professionals with robust, ethics-free and relatively high 


\section{ACCEPTED MANUSCRIPT}

throughput tools for screening the digestibility of food and understanding the effect of processing conditions on the digestive fate of certain food constituents.

\section{Acknowledgments}

The authors of this review are members of the INFOGEST network "Improving health properties of food by sharing our knowledge on the digestive process" 


\section{References}

Adt, I., Dupas, C., Boutrou, R., Oulahal, N., Noel, C., Molle, D., Jouvet, T., and Degraeve, P. (2011). Identification of caseinophosphopeptides generated through in vitro gastro-intestinal digestion of Beaufort cheese. International Dairy Journal. 21: 129-134.

Alminger, M., Aura, A. M., Bohn, T., Dufour, C., El, S. N., Gomes, A., Karakaya, S., Martínez-Cuesta, M. C., McDougall, G. J., Requena, T., and Santos, C. N. (2014). In vitro models for studying secondary plant metabolite digestion and bioaccessibility. Comp Rev Food Sci Food Saf. 13: 413-436.

Alminger, M., Svelander, C. A., Wellner, A., Martinez-Tomas, R., Bialek, L., Larque, E., and Perez-Llamas, F. (2012). Applicability of in Vitro Models in Predicting the in Vivo Bioavailability of Lycopene and $\beta$-Carotene from Differently Processed Soups. Food and Nutrition Sciences. 3: 477-489.

Andre, C. M., Evers, D., Ziebel, J., Guignard, C., Hausman, J. F., Bonierbale, M., Zum Felde, T., and Burgos, G. (2015). In Vitro Bioaccessibility and Bioavailability of Iron from Potatoes with Varying Vitamin C, Carotenoid, and Phenolic Concentrations. J Agric Food Chem. 63: 9012-9021.

Aragón, I. J., Ortiz, D., and Pachón, H. (2012). Comparison between in vitro and in vivo methods to screen iron bioavailability. CYTA - Journal of Food. 10: 103-111.

Araya, H., Contreras, P., Alvina, M., Vera, G., and Pak, N. (2002). A comparison between an in vitro method to determine carbohydrate digestion rate and the glycemic response in young men. European journal of clinical nutrition. 56: 735-739.

Arranz, S., Silvan, J. M., and Saura-Calixto, F. (2010). Nonextractable polyphenols, usually ignored, are the major part of dietary polyphenols: a study on the Spanish diet. Mol Nutr Food Res. 54: 16461658.

Augustin, L., Kendall, C. W., Jenkins, D. J., Willett, W. C., Astrup, A., Barclay, A. W., Björck, I., BrandMiller, J. C., Brighenti, F., and Buyken, A. E. (2015). Glycemic index, glycemic load and glycemic response: an international scientific consensus summit from the international carbohydrate quality consortium (ICQC). Nutrition, Metabolism and Cardiovascular Diseases. 25: 795-815.

Barbe, F., Le Feunteun, S., Remond, D., Menard, O., Jardin, J., Henry, G., Laroche, B., and Dupont, D. (2014). Tracking the in vivo release of bioactive peptides in the gut during digestion: Mass spectrometry peptidomic characterization of effluents collected in the gut of dairy matrix fed mini-pigs. Food Research International. 63: 147-156.

Bax, M. L., Buffiere, C., Hafnaoui, N., Gaudichon, C., Savary-Auzeloux, I., Dardevet, D., Sante-Lhoutellier, V., and Remond, D. (2013a). Effects of Meat Cooking, and of Ingested Amount, on Protein Digestion Speed and Entry of Residual Proteins into the Colon: A Study in Minipigs. Plos One. 8.

Bax, M. L., Sayd, T., Aubry, L., Ferreira, C., Viala, D., Chambon, C., Remond, D., and Sante-Lhoutellier, V. (2013b). Muscle composition slightly affects in vitro digestion of aged and cooked meat: Identification of associated proteomic markers. Food Chemistry. 136: 1249-1262.

Benede, S., Lopez-Exposito, I., Gimenez, G., Grishina, G., Bardina, L., Sampson, H. A., Lopez-Fandino, R., and Molina, E. (2014a). Mapping of IgE epitopes in in vitro gastroduodenal digests of betalactoglobulin produced with human and simulated fluids. Food Research International. 62: 11271133.

Benede, S., Lopez-Exposito, I., Gimenez, G., Grishina, G., Bardina, L., Sampson, H. A., Molina, E., and Lopez-Fandino, R. (2014b). In vitro digestibility of bovine beta-casein with simulated and human oral and gastrointestinal fluids. Identification and IgE-reactivity of the resultant peptides. Food Chemistry. 143: 514-521. 
Benzonana, G., and Desnuelle, P. (1965). Kinetic study of the action of pancreatic lipase on triglycerides in emulsion. Enzymic action in a heterogeneous medium. Biochim. Biophys. Acta. 105: 121-136.

Berti, C., Riso, P., Monti, L. D., and Porrini, M. (2004). In vitro starch digestibility and in vivo glucose response of gluten-free foods and their gluten counterparts. European journal of nutrition. 43: 198-204.

Biehler, E., and Bohn, T. (2010). Methods for assessing aspects of carotenoid bioavailability. Current Nutrition \& Food Science. 6: 44-69.

Biehler, E., Hoffmann, L., Krause, E., and Bohn, T. (2011a). Divalent minerals decrease micellarization and uptake of carotenoids and digestion products into Caco-2 cells. J Nutr. 141: 1769-1776.

Biehler, E., Kaulmann, A., Hoffmann, L., Krause, E., and Bohn, T. (2011b). Dietary and host-related factors influencing carotenoid bioaccessibility from spinach (Spinacia oleracea). Food Chem. 125: 13281334.

Bjorck, I., Granfeldt, Y., Drews, A., and Tovar, J. (1994). An in vitro procedure based on chewing to predict metabolic response to starch in cereal and legume products. The American Journal of Clinical Nutrition. 59: 777S.

Bohn, T. (2008). Bioavailabilty of non-provitamin A carotenoids. Curr Nut Food Sci. 4: 240-258.

Bohn, T. (2014). Dietary factors affecting polyphenol bioavailability. Nutr Rev. 72: 429-452.

Bohn, T., Blackwood, M., Francis, D., Tian, Q., Schwartz, S. J., and Clinton, S. K. (2013). Bioavailability of phytochemical constituents from a novel soy fortified lycopene rich tomato juice developed for targeted cancer prevention trials. Nutr Cancer. 65: 919-929.

Bohn, T., Davidsson, L., Walczyk, T., and Hurrell, R. F. (2004a). Fractional magnesium absorption is significantly lower in human subjects from a meal served with an oxalate-rich vegetable, spinach, as compared with a meal served with kale, a vegetable with a low oxalate content. $\mathrm{Br} J$ Nutr. 91: 601-606.

Bohn, T., Davidsson, L., Walczyk, T., and Hurrell, R. F. (2004b). Phytic acid added to white-wheat bread inhibits fractional apparent magnesium absorption in humans. Am J Clin Nutr. 79: 418-423.

Bohn, T., McDougall, G. J., Alegria, A., Alminger, M., Arrigoni, E., Aura, A. M., Brito, C., Cilla, A., El, S. N., Karakaya, S., Martinez-Cuesta, M. C., and Santos, C. N. (2015). Mind the gap-deficits in our knowledge of aspects impacting the bioavailability of phytochemicals and their metabolites--a position paper focusing on carotenoids and polyphenols. Mol Nutr Food Res. 59: 1307-1323.

Bohn, T., Tian, Q., Chitchumroonchokchai, C., Failla, M. L., Schwartz, S. J., Cotter, R., and Waksman, J. A. (2007). Supplementation of test meals with fat-free phytosterol products can reduce cholesterol micellarization during simulated digestion and cholesterol accumulation by Caco- 2 cells. J Agric Food Chem. 55: 267-272.

Borel, P. (2003). Factors affecting intestinal absorption of highly lipophilic food microconstituents (fatsoluble vitamins, carotenoids and phytosterols). Clin Chem Lab Med. 41: 979-994.

Borel, P. (2012). Genetic variations involved in interindividual variability in carotenoid status. Mol Nutr Food Res. 56: 228-240.

Borel, P., Desmarchelier, C., Nowicki, M., and Bott, R. (2015a). A combination of single-nucleotide polymorphisms is associated with interindividual variability in dietary beta-carotene bioavailability in healthy men. $J$ Nutr. 145: 1740-1747.

Borel, P., Desmarchelier, C., Nowicki, M., and Bott, R. (2015b). Lycopene bioavailability is associated with a combination of genetic variants. Free Radic Biol Med. 83: 238-244. 
Borel, P., Desmarchelier, C., Nowicki, M., Bott, R., Morange, S., and Lesavre, N. (2014). Interindividual variability of lutein bioavailability in healthy men: characterization, genetic variants involved, and relation with fasting plasma lutein concentration. Am J Clin Nutr. 100: 168-175.

Bornhorst, G. M., and Singh, R. P. (2012). Bolus formation and disintegration during digestion of food carbohydrates. Comprehensive Reviews in Food Science and Food Safety. 11: 101-118.

Bouayed, J., Deusser, H., Hoffmann, L., and Bohn, T. (2012). Bioaccessible and dialysable polyphenols in selected apple varieties following in vitro digestion vs. their native patterns. Food Chem. 131: 1466-1472.

Bouayed, J., Hoffmann, L., and Bohn, T. (2011). Total phenolics, flavonoids, anthocyanins and antioxidant activity following simulated gastro-intestinal digestion and dialysis of apple varieties: Bioaccessibility and potential uptake. Food Chem. 128: 14-21.

Boutrou, R., Coirre, E., Jardin, J., and Leonil, J. (2010). Phosphorylation and Coordination Bond of Mineral Inhibit the Hydrolysis of the beta-Casein (1-25) Peptide by Intestinal Brush-Border Membrane Enzymes. Journal of Agricultural and Food Chemistry. 58: 7955-7961.

Boutrou, R., Gaudichon, C., Dupont, D., Jardin, J., Airinei, G., Marsset-Baglieri, A., Benamouzig, R., Tome, D., and Leonil, J. (2013). Sequential release of milk protein-derived bioactive peptides in the jejunum in healthy humans. American Journal of Clinical Nutrition. 97: 1314-1323.

Brand-Miller, J., and Holt, S. (2004). Testing the glycaemic index of foods: in vivo, not in vitro. European journal of clinical nutrition. 58: 700-701.

Brantl, V., Teschemacher, H., Blasig, J., Henschen, A., and Lottspeich, F. (1981). Opioid Activities of BetaCasomorphins. Life Sciences. 28: 1903-1909.

Brantl, V., Teschemacher, H., Henschen, A., and Lottspeich, F. (1979). Novel Opioid Peptides Derived from Casein (Beta-Casomorphins) .1. Isolation from Bovine Casein Peptone. Hoppe-Seylers Zeitschrift fur Physiologische Chemie. 360: 1211-1216.

Brown, E. M., Nitecki, S., Pereira-Caro, G., McDougall, G. J., Stewart, D., Rowland, I., Crozier, A., and Gill, C. I. R. (2014). Comparison of in vivo and in vitro digestion on polyphenol composition in lingonberries: Potential impact on colonic health. Biofactors. 40: 611-623.

Butterworth, P. J., Warren, F. J., and Ellis, P. R. (2011). Human $\alpha$-amylase and starch digestion: An interesting marriage. Starch - Stärke. 63: 395-405.

Caballero, B., Allen, L. H., and Prentice, A. (2012). Encyclopedia of human nutrition, 3rd Edition. Academic press.

Carbonell-Capella, J. M., Buniowska, M., Barba, F. J., Esteve, M. J., and Frígola, A. (2014). Analytical Methods for Determining Bioavailability and Bioaccessibility of Bioactive Compounds from Fruits and Vegetables: A Review. Comprehensive Reviews in Food Science and Food Safety. 13: 155171.

Carrière, F., Barrowman, J. A., Verger, R., and Laugier, R. (1993). Secretion and contribution to lipolysis of gastric and pancreatic lipases during a test meal in humans. Gastroenterology. 105: 876-888.

Carriere, F., Renou, C., Lopez, V., De Caro, J., Ferrato, F., Lengsfeld, H., De Caro, A., Laugier, R., and Verger, R. (2000). The specific activities of human digestive lipases measured from the in vivo and in vitro lipolysis of test meals. Gastroenterology. 119: 949-960.

Carrière, F., Renou, C., Ransac, S., Lopez, V., De Caro, J., Ferrato, F., De Caro, A., Fleury, A., SanwaldDucray, P., Lengsfeld, H., Beglinger, C., Hadvary, P., Verger, R., and Laugier, R. (2001). Inhibition of gastrointestinal lipolysis by Orlistat during digestion of test meals in healthy volunteers. Am. J. Physiol. Gastrointest. Liver. Physiol. 281: G16-28. 
Casiraghi, M., Brighenti, F., and Testolin, G. (1992). Lack of effect of high temperature drying on digestibility of starch in spaghetti. Journal of Cereal Science. 15: 165-174.

Chabance, B., Marteau, P., Rambaud, J. C., Migliore-Samour, D., Boynard, M., Perrotin, P., Guillet, R., Jolles, P., and Fiat, A. M. (1998). Casein peptide release and passage to the blood in humans during digestion of milk or yogurt. Biochimie. 80: 155-165.

Cho, J. H., and Kim, I. H. (2011). Evaluation of the Apparent lleal Digestibility (AID) of Protein and Amino Acids in Nursery Diets by In vitro and In vivo Methods. Asian-Australasian Journal of Animal Sciences. 24: 1007-1010.

Contreras, M., Carron, R., Montero, M., Ramos, M., and Recio, I. (2009). Novel casein-derived peptides with antihypertensive activity. International Dairy Journal. 19: 566-573.

Conway, R. E., Geissler, C. A., Hider, R. C., Thompson, R. P., and Powell, J. J. (2006). Serum iron curves can be used to estimate dietary iron bioavailability in humans. J Nutr. 136: 1910-1914.

Cook, J. D., and Monsen, E. R. (1977). Vitamin C, the common cold, and iron absorption. Am J Clin Nutr. 30: 235-241.

Corte-Real, J., Iddir, M., Soukoulis, C., Richling, E., Hoffmann, L., and Bohn, T. (2016). Effect of divalent minerals on the bioaccessibility of pure carotenoids and on physical properties of gastrointestinal fluids. Food Chem. 197: 546-553.

Corte-Real, J., Richling, E., Hoffmann, L., and Bohn, T. (2014). Selective factors governing in vitro betacarotene bioaccessibility: negative influence of low filtration cutoffs and alterations by emulsifiers and food matrices. Nutr Res. 34: 1101-1110.

Couedelo, L., Amara, S., Lecomte, M., Meugnier, E., Monteil, J., Fonseca, L., Pineau, G., Cansell, M., Carriere, F., Michalski, M. C., and Vaysse, C. (2015). Impact of various emulsifiers on ALA bioavailability and chylomicron synthesis through changes in gastrointestinal lipolysis. Food Funct. 6: 1726-1735.

Dallas, D. C., Guerrero, A., Khaldi, N., Borghese, R., Bhandari, A., Underwood, M. A., Lebrilla, C. B., German, J. B., and Barile, D. (2014). A Peptidomic Analysis of Human Milk Digestion in the Infant Stomach Reveals Protein-Specific Degradation Patterns. Journal of Nutrition. 144: 815-820.

Darragh, A. J., and Hodgkinson, S. M. (2000). Quantifying the digestibility of dietary protein. Journal of Nutrition. 130: 1850S-1856S.

Davidsson, L., Dimitriou, T., Boy, E., Walczyk, T., and Hurrell, R. F. (2002). Iron bioavailability from ironfortified Guatemalan meals based on corn tortillas and black bean paste. Am J Clin Nutr. 75: 535539.

Day, L., Golding, M., Xu, M., Keogh, J., Clifton, P., and Wooster, T. J. (2014). Tailoring the digestion of structured emulsions using mixed monoglyceride-caseinate interfaces. Food Hydrocolloids. 36: 151-161.

De Noni, I. (2008). Release of beta-casomorphins 5 and 7 during simulated gastro-intestinal digestion of bovine beta-casein variants and milk-based infant formulas. Food Chemistry. 110: 897-903.

Delorme, V., Dhouib, R., Canaan, S., Fotiadu, F., Carriere, F., and Cavalier, J.-F. (2011). Effects of surfactants on lipase structure, activity, and inhibition. Pharm. Res. 28: 1831-1842.

Dickinson, E. (1997). Enzymic crosslinking as a tool for food colloid rheology control and interfacial stabilization. Trends in Food Science \& Technology. 8: 334-339.

Dona, A. C., Pages, G., Gilbert, R. G., and Kuchel, P. W. (2010). Digestion of starch: "In vivo" and "in vitro" kinetic models used to characterise oligosaccharide or glucose release. Carbohydrate Polymers. 80: 599-617. 
Dupont, D., Mandalari, G., Molle, D., Jardin, J., Leonil, J., Faulks, R. M., Wickham, M. S. J., Mills, E. N. C., and Mackie, A. R. (2010a). Comparative resistance of food proteins to adult and infant in vitro digestion models. Molecular Nutrition \& Food Research. 54: 767-780.

Dupont, D., Mandalari, G., Molle, D., Jardin, J., Rolet-Repecaud, O., Duboz, G., Leonil, J., Mills, E. N. C., and Mackie, A. R. (2010b). Food processing increases casein resistance to simulated infant digestion. Molecular Nutrition \& Food Research. 54: 1677-1689.

Egger, L., Ménard, O., Delgado-Andrade, C., Alvito, P., Assunção, R., Balance, S., Barberá, R., Brodkorb, A., Cattenoz, T., Clemente, A., Comi, I., Dupont, D., Garcia-Llatas, G., Lagarda, M. J., Le Feunteun, S., JanssenDuijghuijsen, L., Karakaya, S., Lesmes, U., Mackie, A. R., Martins, C., Meynier, A., Miralles, B., Murray, B. S., Pihlanto, A., Picariello, G., Santos, C. N., Simsek, S., Recio, I., Rigby, N., Rioux, L.-E., Stoffers, H., Tavares, A., Tavares, L., Turgeon, S., Ulleberg, E. K., Vegarud, G. E., Vergères, G., and Portmann, R. (2016). The harmonized INFOGEST in vitro digestion method: From knowledge to action. Food Research International: 217-225.

Ells, L. J., Seal, C. J., Kettlitz, B., Bal, W., and Mathers, J. C. (2005). Postprandial glycaemic, lipaemic and haemostatic responses to ingestion of rapidly and slowly digested starches in healthy young women. British Journal of Nutrition. 94: 948-955.

Englyst, H. N., Kingman, S., and Cummings, J. (1992). Classification and measurement of nutritionally important starch fractions. European journal of clinical nutrition. 46: S33-50.

Englyst, H. N., Veenstra, J., and Hudson, G. J. (1996). Measurement of rapidly available glucose (RAG) in plant foods: a potential in vitro predictor of the glycaemic response. British Journal of Nutrition. 75: 327-337.

Englyst, K. N., Englyst, H. N., Hudson, G. J., Cole, T. J., and Cummings, J. H. (1999). Rapidly available glucose in foods: an in vitro measurement that reflects the glycemic response. The American Journal of Clinical Nutrition. 69: 448-454.

Erk, T., Renouf, M., Williamson, G., Melcher, R., Steiling, H., and Richling, E. (2014). Absorption and isomerization of caffeoylquinic acids from different foods using ileostomist volunteers. Eur $J$ Nutr. 53: 159-166.

Etcheverry, P., Grusak, M. A., and Fleige, L. E. (2012). Application of in vitro bioaccessibility and bioavailability methods for calcium, carotenoids, folate, iron, magnesium, polyphenols, zinc, and vitamins B(6), B(12), D, and E. Front Physiol. 3: 317.

Failla, M. L., Chitchumroonchokchai, C., and Ishida, B. K. (2008). In vitro micellarization and intestinal cell uptake of cis isomers of lycopene exceed those of all-trans lycopene. J Nutr. 138: 482-486.

Fernandez-Tome, S., Martinez-Maqueda, D., Giron, R., Goicoechea, C., Miralles, B., and Recio, I. (2016). Novel peptides derived from alpha(s1)-casein with opioid activity and mucin stimulatory effect on HT29-MTX cells. Journal of Functional Foods. 25: 466-476.

Ferrer-Mairal, A., Penalva-Lapuente, C., Iglesia, I., Urtasun, L., De Miguel-Etayo, P., Remón, S., Cortés, E., and Moreno, L. (2012). In vitro and in vivo assessment of the glycemic index of bakery products: influence of the reformulation of ingredients. European journal of nutrition. 51: 947-954.

Fontana, A., Spolaore, B., Mero, A., and Veronese, F. M. (2008). Site-specific modification and PEGylation of pharmaceutical proteins mediated by transglutaminase. Advanced Drug Delivery Reviews. 60: 13-28.

Fuller, M. F., and Tome, D. (2005). In vivo determination of amino acid Bioavailability in humans and model animals. Journal of AOAC International. 88: 923-934.

Fuqua, B. K., Vulpe, C. D., and Anderson, G. J. (2012). Intestinal iron absorption. Journal of Trace Elements in Medicine and Biology. 26: 115-119. 
Gargouri, Y., Piéroni, G., Rivière, C., Saunière, J.-F., Lowe, P. A., Sarda, L., and Verger, R. (1986). Kinetic assay of human gastric lipase on short- and long-chain triacylglycerol emulsions. Gastroenterology. 91: 919-925.

Gibson, N., Schönfeldt, H. C., and Pretorius, B. (2011). Development of a rapid assessment method for the prediction of the glycemic index. Journal of Food Composition and Analysis. 24: 750-754.

Gil-Izquierdo, A., Zafrilla, P., and Tomás-Barberán, F. A. (2002). An in vitro method to simulate phenolic compound release from the food matrix in the gastrointestinal tract. European Food Research and Technology. 214: 155-159.

Gilani, G. S., Cockell, K. A., and Sepehr, E. (2005). Effects of antinutritional factors on protein digestibility and amino acid availability in foods. Journal of AOAC International. 88: 967-987.

Golding, M., Wooster, T. J., Day, L., Xu, M., Lundin, L., Keogh, J., and Clifton, P. (2011). Impact of gastric structuring on the lipolysis of emulsified lipids. Soft Matter. 7: 3513-3523.

Goñi, I., Garcia-Alonso, A., and Saura-Calixto, F. (1997). A starch hydrolysis procedure to estimate glycemic index. Nutrition Research. 17: 427-437.

Goni, I., Serrano, J., and Saura-Calixto, F. (2006). Bioaccessibility of beta-carotene, lutein, and lycopene from fruits and vegetables. J Agric Food Chem. 54: 5382-5387.

Gropper, S., and Smith, J. (2013). Advanced nutrition and human metabolism, 6th Edition. Cengage Learning, United States of America.

Guo, Y., Mah, E., and Bruno, R. S. (2014). Quercetin bioavailability is associated with inadequate plasma vitamin $C$ status and greater plasma endotoxin in adults. Nutrition. 30: 1279-1286.

Hernandez-Ledesma, B., Amigo, L., Ramos, M., and Recio, I. (2004). Release of angiotensin converting enzyme-inhibitory peptides by simulated gastrointestinal digestion of infant formulas. International Dairy Journal. 14: 889-898.

Hernandez-Ledesma, B., Quiros, A., Amigo, L., and Recio, I. (2007). Identification of bioactive peptides after digestion of human milk and infant formula with pepsin and pancreatin. International Dairy Journal. 17: 42-49.

Hurrell, R. (2007). Linking the bioavailability of iron compounds to the efficacy of iron-fortified foods. Int J Vitam Nutr Res. 77: 166-173.

ISO (2010). ISO 26642-2010. In: Food Products-Determination of the Glycaemic Index (GI) and Recommendation for Food Classification.

Jenkins, D., Ghafari, H., Wolever, T., Taylor, R., Jenkins, A., Barker, H., Fielden, H., and Bowling, A. (1982). Relationship between rate of digestion of foods and post-prandial glycaemia. Diabetologia. 22: 450-455.

Jenkins, D., Wolever, T., Taylor, R. H., Barker, H., Fielden, H., Baldwin, J. M., Bowling, A. C., Newman, H. C., Jenkins, A. L., and Goff, D. V. (1981). Glycemic index of foods: a physiological basis for carbohydrate exchange. The American Journal of Clinical Nutrition. 34: 362-366.

Jinsmaa, Y., and Yoshikawa, M. (1999). Enzymatic release of neocasomorphin and beta-casomorphin from bovine beta-casein. Peptides. 20: 957-962.

Juvonen, K. R., Macierzanka, A., Lille, M. E., Laaksonen, D. E., Mykkanen, H. M., Niskanen, L. K., Pihlajamaki, J., Makela, K. A., Mills, C. E. N., Mackie, A. R., Malcolm, P., Herzig, K. H., Poutanen, K. S., and Karhunen, L. J. (2015). Cross-linking of sodium caseinate-structured emulsion with transglutaminase alters postprandial metabolic and appetite responses in healthy young individuals. British Journal of Nutrition. 114: 418-429.

Kalt, W., Liu, Y., McDonald, J. E., Vinqvist-Tymchuk, M. R., and Fillmore, S. A. (2014). Anthocyanin metabolites are abundant and persistent in human urine. J Agric Food Chem. 62: 3926-3934. 
Kaulmann, A., Andre, C. M., Schneider, Y. J., Hoffmann, L., and Bohn, T. (2015). Carotenoid and polyphenol bioaccessibility and cellular uptake from plum and cabbage varieties. Food Chem. 197 (Pt A): 325-332.

Keogh, J. B., Wooster, T. J., Golding, M., Day, L., Otto, B., and Clifton, P. M. (2011). Slowly and rapidly digested fat emulsions are equally satiating but their triglycerides are differentially absorbed and metabolized in humans. Journal of Nutrition. 141: 809-815.

Kitabatake, N., and Kinekawa, Y. I. (1998). Digestibility of bovine milk whey protein and betalactoglobulin in vitro and in vivo. Journal of Agricultural and Food Chemistry. 46: 4917-4923.

Kulkarni, S. D., Acharya, R., Rajurkar, N. S., and Reddy, A. V. R. (2007). Evaluation of bioaccessibility of some essential elements from wheatgrass (Triticum aestivum L.) by in vitro digestion method. Food Chemistry. 103: 681-688.

Liang, L., Wu, X., Zhao, T., Zhao, J., Li, F., Zou, Y., Mao, G., and Yang, L. (2012). In vitro bioaccessibility and antioxidant activity of anthocyanins from mulberry (Morus atropurpurea Roxb.) following simulated gastro-intestinal digestion. Food Research International. 46: 76-82.

Macierzanka, A., Bordron, F., Rigby, N. M., Mills, E. N. C., Lille, M., Poutanen, K., and Mackie, A. R. (2011). Transglutaminase cross-linking kinetics of sodium caseinate is changed after emulsification. Food Hydrocolloids. 25: 843-850.

Macierzanka, A., Bottger, F., Rigby, N. M., Lille, M., Poutanen, K., Mills, E. N. C., and Mackie, A. R. (2012). Enzymatically Structured Emulsions in Simulated Gastrointestinal Environment: Impact on Interfacial Proteolysis and Diffusion in Intestinal Mucus. Langmuir. 28: 17349-17362.

Maeno, M., Yamamoto, N., and Takano, T. (1996). Identification of an antihypertensive peptide from casein hydrolysate produced by a proteinase from Lactobacillus helveticus CP790. Journal of Dairy Science. 79: 1316-1321.

Manach, C., Williamson, G., Morand, C., Scalbert, A., and Remesy, C. (2005). Bioavailability and bioefficacy of polyphenols in humans. I. Review of 97 bioavailability studies. Am J Clin Nutr. 81: 230S-242S.

Mandalari, G., Bisignano, C., Filocamo, A., Chessa, S., Saro, M., Torre, G., Faulks, R. M., and Dugo, P. (2013). Bioaccessibility of pistachio polyphenols, xanthophylls, and tocopherols during simulated human digestion. Nutrition. 29: 338-344.

Mandalari, G., Mackie, A. M., Rigby, N. M., Wickham, M. S., and Mills, E. (2009). Physiological phosphatidylcholine protects bovine beta-lactoglobulin from simulated gastrointestinal proteolysis. Molecular Nutrition \& Food Research. 53: S131-S139.

Martinez-Maqueda, D., Miralles, B., Recio, I., and Hernandez-Ledesma, B. (2012). Antihypertensive peptides from food proteins: a review. Food \& Function. 3: 350-361.

Meisel, H. (1986). Chemical Characterization and Opioid Activity of An Exorphin Isolated from In vivo Digests of Casein. FEBS Letters. 196: 223-227.

Meisel, H., Bernard, H., Fairweather-Tait, S., FitzGerald, R. J., Hartmann, R., Lane, C. N., McDonagh, D., Teucher, B., and Wal, J. M. (2003). Detection of caseinophosphopeptides in the distal ileostomy fluid of human subjects. British Journal of Nutrition. 89: 351-358.

Meisel, H., and FitzGerald, R. J. (2003). Biofunctional peptides from milk proteins: Mineral binding and cytomodulatory effects. Current Pharmaceutical Design. 9: 1289-1295.

Miller, D. D., Schricker, B. R., Rasmussen, R. R., and Van Campen, D. (1981). An in vitro method for estimation of iron availability from meals. Am J Clin Nutr. 34: 2248-2256.

Minekus, M., Alminger, M., Alvito, P., Ballance, S., Bohn, T., Bourlieu, C., Carriere, F., Boutrou, R., Corredig, M., Dupont, D., Dufour, C., Egger, L., Golding, M., Karakaya, S., Kirkhus, B., Le 
Feunteun, S., Lesmes, U., Macierzanka, A., Mackie, A., Marze, S., McClements, D. J., Menard, O., Recio, I., Santos, C. N., Singh, R. P., Vegarud, G. E., Wickham, M. S. J., Weitschies, W., and Brodkorb, A. (2014). A standardised static in vitro digestion method suitable for food - an international consensus. Food \& Function. 5: 1113-1124.

Minekus, M., Smeets-Peeters, M., Bernalier, A., Marol-Bonnin, S., Havenaar, R., Marteau, P., Alric, M., Fonty, G., and Huis in't Veld, J. H. J. (1999). Computer-controlled system to simulate conditions of the large intestine with peristaltic mixing, water absorption and absorption of fermentation products. Appl. Microbiol. Biotechnol. 53: 108-114.

Miquel, E., Alegria, A., Barbera, R., and Farre, R. (2006). Casein phosphopeptides released by simulated gastrointestinal digestion of infant formulas and their potential role in mineral binding. International Dairy Journal. 16: 992-1000.

Miquel, E., Gomez, J. N., Alegria, A., Barbera, R., Farre, R., and Recio, I. (2005). Identification of casein phosphopeptides released after simulated digestion of milk-based infant formulas. Journal of Agricultural and Food Chemistry. 53: 3426-3433.

Monro, J. A., and Mishra, S. (2010). Glycemic impact as a property of foods is accurately measured by an available carbohydrate method that mimics the glycemic response. The Journal of nutrition. 140: 1328-1334.

Monro, J. A., Mishra, S., and Venn, B. (2010). Baselines representing blood glucose clearance improve in vitro prediction of the glycaemic impact of customarily consumed food quantities. Br J Nutr. 103: 295-305.

Moran-Valero, M. I., Martin, D., Torrelo, G., Reglero, G., and Torres, C. F. (2012). Phytosterols esterified with conjugated linoleic acid. In vitro intestinal digestion and interaction on cholesterol bioaccessibility. J Agric Food Chem. 60: 11323-11330.

Moughan, P. J. (2003). Amino acid availability: aspects of chemical analysis and bioassay methodology. Nutrition Research Reviews. 16: 127-141.

Nielsen, I. L., and Williamson, G. (2007). Review of the factors affecting bioavailability of soy isoflavones in humans. Nutr Cancer. 57: 1-10.

O'Neill, M. E., and Thurnham, D. I. (1998). Intestinal absorption of beta-carotene, lycopene and lutein in men and women following a standard meal: response curves in the triacylglycerol-rich lipoprotein fraction. Br J Nutr. 79: 149-159.

Perez-Jimenez, J., Diaz-Rubio, M. E., and Saura-Calixto, F. (2013). Non-extractable polyphenols, a major dietary antioxidant: occurrence, metabolic fate and health effects. Nutr Res Rev. 26: 118-129.

Picariello, G., Ferranti, P., Fierro, O., Mamone, G., Caira, S., Di Luccia, A., Monica, S., and Addeo, F. (2010). Peptides surviving the simulated gastrointestinal digestion of milk proteins: Biological and toxicological implications. Journal of Chromatography $B$ - Analytical Technologies in the Biomedical and Life Sciences. 878: 295-308.

Picariello, G., Miralles, B., Mamone, G., Sanchez-Rivera, L., Recio, I., Addeo, F., and Ferranti, P. (2015). Role of intestinal brush border peptidases in the simulated digestion of milk proteins. Molecular Nutrition \& Food Research. 59: 948-956.

Quiros, A., Ramos, M., Muguerza, B., Delgado, M. A., Miguel, M., Aleixandre, A., and Recio, I. (2007). Identification of novel antihypertensive peptides in milk fermented with Enterococcus faecalis. International Dairy Journal. 17: 33-41.

Qureshi, T. M., Vegarud, G. E., Abrahamsen, R. K., and Skeie, S. (2013). Angiotensin I-converting enzymeinhibitory activity of the Norwegian autochthonous cheeses Gamalost and Norvegia after in vitro human gastrointestinal digestion. Journal of Dairy Science. 96: 838-853. 
Reboul, E., and Borel, P. (2011). Proteins involved in uptake, intracellular transport and basolateral secretion of fat-soluble vitamins and carotenoids by mammalian enterocytes. Prog Lipid Res. 50: 388-402.

Reboul, E., Richelle, M., Perrot, E., smoulins-Malezet, C., Pirisi, V., and Borel, P. (2006). Bioaccessibility of carotenoids and vitamin E from their main dietary sources. J Agric Food Chem. 54: 8749-8755.

Rozan, P., Lamghari, R., Linder, M., Villaume, C., Fanni, J., Parmentier, M., and Mejean, L. (1997). In vivo and in vitro digestibility of soybean, lupine, and rapeseed meal proteins after various technological processes. Journal of Agricultural and Food Chemistry. 45: 1762-1769.

Sanchez-Rivera, L., Diezhandino, I., Gomez-Ruiz, J. A., Fresno, J. M., Miralles, B., and Recio, I. (2014). Peptidomic study of Spanish blue cheese (Valdeon) and changes after simulated gastrointestinal digestion. Electrophoresis. 35: 1627-1636.

Sanchez-Rivera, L., Menard, O., Recio, I., and Dupont, D. (2015). Peptide mapping during dynamic gastric digestion of heated and unheated skimmed milk powder. Food Research International. 77: 132139.

Sanchez-Rivera, L., Santos, P. F., Miralles, B., Carron, R., Montero, M. J., and Recio, I. (2016). Peptide fragments from beta-casein $\mathrm{f}(134-138), \mathrm{HLPLP}$, generated by the action of rat blood plasma peptidases show potent antihypertensive activity. Food Research International. 88: 348-353.

Sandberg, A. S. (2005). Methods and options in vitro dialyzability; benefits and limitations. Int J Vitam Nutr Res. 75: 395-404.

Saunders, R. M., Connor, M. A., Booth, A. N., Bickoff, E. M., and Kohler, G. O. (1973). MEASUREMENT OF DIGESTIBILITY OF ALFALFA PROTEIN CONCENTRATES BY IN-VIVO AND IN-VITRO METHODS. Journal of Nutrition. 103: 530-535.

Sayd, T., Chambon, C., and Santé-Lhoutellier, V. (2016). Quantification of peptides released during in vitro digestion of cooked meat. Food Chemistry. 197: 1311-1323.

Scholz-Ahrens, K. E., Ade, P., Marten, B., Weber, P., Timm, W., Acil, Y., Gluer, C. C., and Schrezenmeir, J. (2007). Prebiotics, probiotics, and synbiotics affect mineral absorption, bone mineral content, and bone structure. J Nutr. 137: 838s-846s.

Seal, C. J., Daly, M. E., Thomas, L. C., Bal, W., Birkett, A. M., Jeffcoat, R., and Mathers, J. C. (2003). Postprandial carbohydrate metabolism in healthy subjects and those with type 2 diabetes fed starches with slow and rapid hydrolysis rates determined in vitro. British Journal of Nutrition. 90 : 853-864.

Setchell, K. D., Faughnan, M. S., Avades, T., Zimmer-Nechemias, L., Brown, N. M., Wolfe, B. E., Brashear, W. T., Desai, P., Oldfield, M. F., Botting, N. P., and Cassidy, A. (2003). Comparing the pharmacokinetics of daidzein and genistein with the use of 13C-labeled tracers in premenopausal women. Am J Clin Nutr. 77: 411-419.

Steingoetter, A., Radovic, T., Buetikofer, S., Curcic, J., Menne, D., Fried, M., Schwizer, W., and Wooster, T. J. (2015). Imaging gastric structuring of lipid emulsions and its effect on gastrointestinal function: a randomized trial in healthy subjects. Am. J. Clin. Nutr. 101: 714-724.

Svedberg, J., Dehaas, J., Leimenstoll, G., Paul, F., and Teschemacher, H. (1985). Demonstration of BetaCasomorphin Immunoreactive Materials in In vitro Digests of Bovine-Milk and in Small-Intestine Contents After Bovine-Milk Ingestion in Adult Humans. Peptides. 6: 825-830.

Teschemacher, H., Koch, G., and Brantl, V. (1997). Milk protein-derived opioid receptor ligands. Biopolymers. 43: 99-117. 
Tyssandier, V., Reboul, E., Dumas, J. F., Bouteloup-Demange, C., Armand, M., Marcand, J., Sallas, M., and Borel, P. (2003). Processing of vegetable-borne carotenoids in the human stomach and duodenum. Am J Physiol Gastrointest Liver Physiol. 284: G913-G923.

Unlu, N. Z., Bohn, T., Clinton, S. K., and Schwartz, S. J. (2005). Carotenoid absorption from salad and salsa by humans is enhanced by the addition of avocado or avocado oil. J Nutr. 135: 431-436.

Van Loo-Bouwman, C. A., Naber, T. H., Minekus, M., van Breemen, R. B., Hulshof, P. J., and Schaafsma, G. (2014). Food matrix effects on bioaccessibility of beta-carotene can be measured in an in vitro gastrointestinal model. J Agric Food Chem. 62: 950-955.

Van Loo-Bouwman, C. A., Naber, T. H., van Breemen, R. B., Zhu, D., Dicke, H., Siebelink, E., Hulshof, P. J., Russel, F. G., Schaafsma, G., and West, C. E. (2010). Vitamin A equivalency and apparent absorption of beta-carotene in ileostomy subjects using a dual-isotope dilution technique. $\mathrm{Br} J$ Nutr. 103: 1836-1843.

Veda, S., Kamath, A., Platel, K., Begum, K., and Srinivasan, K. (2006). Determination of bioaccessibility of beta-carotene in vegetables by in vitro methods. Mol Nutr Food Res. 50: 1047-1052.

Venn, B. J., Wallace, A. J., Monro, J. A., Perry, T., Brown, R., Frampton, C., and Green, T. J. (2006). The glycemic load estimated from the glycemic index does not differ greatly from that measured using a standard curve in healthy volunteers. The Journal of nutrition. 136: 1377-1381.

Vetrani, C., Rivellese, A. A., Annuzzi, G., Adiels, M., Boren, J., Mattila, I., Oresic, M., and Aura, A. M. (2016). Metabolic transformations of dietary polyphenols: comparison between in vitro colonic and hepatic models and in vivo urinary metabolites. J Nutr Biochem. 33: 111-118.

Vors, C., Capolino, P., Guerin, C., Meugnier, E., Pesenti, S., Chauvin, M. A., Monteil, J., Peretti, N., Cansell, M., Carriere, F., and Michalski, M. C. (2012). Coupling in vitro gastrointestinal lipolysis and Caco2 cell cultures for testing the absorption of different food emulsions. Food Funct. 3: 537-546.

Walter, T., Pizarro, F., and Olivares, M. (2003). Iron bioavailability in corn-masa tortillas is improved by the addition of disodium EDTA. J Nutr. 133: 3158-3161.

Wickham, M., and Faulks, R. (2007). Apparatus, system and method. Plant Bioscience Limited, UK .

Woolnough, J. W., Monro, J. A., Brennan, C. S., and Bird, A. R. (2008). Simulating human carbohydrate digestion in vitro: a review of methods and the need for standardisation. International journal of food science \& technology. 43: 2245-2256.

Wooster, T. J., Day, L., Xu, M., Golding, M., Oiseth, S., Keogh, J., and Clifton, P. (2014). Impact of different biopolymer networks on the digestion of gastric structured emulsions. Food Hydrocolloids. 36: 102-114.

Yun, S., Habicht, J. P., Miller, D. D., and Glahn, R. P. (2004). An in vitro digestion/Caco-2 cell culture system accurately predicts the effects of ascorbic acid and polyphenolic compounds on iron bioavailability in humans. J Nutr. 134: 2717-2721.

Zubik, L., and Meydani, M. (2003). Bioavailability of soybean isoflavones from aglycone and glucoside forms in American women. Am J Clin Nutr. 77: 1459-1465. 


\section{ACCEPTED MANUSCRIPT}

Table 1

\begin{tabular}{|c|c|c|c|c|}
\hline $\begin{array}{l}\text { Bioactive peptide (protein } \\
\text { fragment) (reference) }\end{array}$ & $\begin{array}{l}\text { Ingested } \\
\text { food }\end{array}$ & $\begin{array}{l}\text { Intestinal } \\
\text { tract part }\end{array}$ & Species & Reference \\
\hline $\begin{array}{l}\text { KVLPVPQ } \quad(\beta-C N \quad 169- \\
175)\end{array}$ & $\begin{array}{l}\text { Human } \\
\text { milk }\end{array}$ & Stomach & $\begin{array}{l}\text { Human } \\
\text { (newborn) }\end{array}$ & Dallas et al., 2014 \\
\hline $\begin{array}{l}\text { (Maeno et al., 1996) } \\
\text { AVPYPQR ( } \beta-C N \quad \text { 177- } \\
\text { 183) } \\
\text { (Karaki et al., } 1990)\end{array}$ & $\begin{array}{l}\text { Human } \\
\text { milk }\end{array}$ & Stomach & $\begin{array}{l}\text { Human } \\
\text { (newborn) }\end{array}$ & Dallas et al., 2014 \\
\hline $\begin{array}{l}\text { AYFYPEL }\left(\alpha_{\mathrm{s} 1}-\mathrm{CN} 143-\right. \\
149) \\
(\text { Contreras et al., } 2009)\end{array}$ & $\begin{array}{l}\text { Milk or } \\
\text { yogurt }\end{array}$ & $\begin{array}{l}\text { Stomach and } \\
\text { duodenum }\end{array}$ & Human & Chabance et al., 1998 \\
\hline $\begin{array}{l}\text { YFYPEL }\left(\alpha_{\mathrm{s}_{1}-\mathrm{CN}} 144-149\right) \\
\text { (Sánchez-Rivera et al., } \\
2014)\end{array}$ & Milk & Duodenum & Human & Chabance et al., 1998 \\
\hline $\begin{array}{l}\text { MKPWIQPK }\left(\alpha_{\mathrm{s} 2} 190-197\right) \\
\text { (Maeno et al., } 1996)\end{array}$ & Milk & Duodenum & Pig & Barbé et al., 2014 \\
\hline $\begin{array}{l}\text { FFVAPFPEVFGK }\left(\alpha_{\mathrm{s} 1}-\mathrm{CN}\right. \\
23-34) \\
\text { (Karaki et al., } 1990)\end{array}$ & Milk & Duodenum & Pig & Barbé et al., 2014 \\
\hline $\begin{array}{l}\text { YPFPGPIPN ( } \beta-\mathrm{CN} \text { 60-68) } \\
\text { (Saito et al., 2000) }\end{array}$ & Casein & Jejunum & Human & Boutrou et al., 2013 \\
\hline $\begin{array}{l}\text { LHLPLP ( } \beta \text {-CN 133-138) } \\
\text { (Quirós et al., 2007) }\end{array}$ & Casein & Jejunum & Human & Boutrou et al., 2013 \\
\hline $\begin{array}{l}\text { TPVVVPPFLQP } \quad(\beta-\mathrm{CN} \\
80-90)\end{array}$ & $\begin{array}{l}\text { Infant } \\
\text { formula }\end{array}$ & Jejunum & $\begin{array}{l}\text { Pig } \\
\text { (newborn) }\end{array}$ & $\begin{array}{l}\text { Bouzerzour et al., } \\
2012\end{array}$ \\
\hline
\end{tabular}

${ }^{\mathrm{a}}$ Fragment comprising antihypertensive sequence 


\section{ACCEPTED MANUSCRIPT}

Table 2

\begin{tabular}{|c|c|c|c|}
\hline & \multicolumn{2}{|c|}{ Meat } & \multirow[t]{2}{*}{$\mathrm{P}$} \\
\hline In vitro & Pork, $30 \mathrm{~min}$ at $70^{\circ} \mathrm{C}$ & $\begin{array}{l}\text { Pork, } 30 \text { min at } \\
140^{\circ} \mathrm{C}\end{array}$ & \\
\hline \multicolumn{4}{|l|}{ Pepsin digestion } \\
\hline Maximal degradation (ODmax) & 0.106 & 0.122 & $* * *$ \\
\hline Maximal rate of digestion & 0.163 & 0.126 & $* * *$ \\
\hline \multicolumn{4}{|l|}{$(\Delta \mathrm{OD} / \mathrm{h})$} \\
\hline Half-life time (min) & 31 & 45 & $* * *$ \\
\hline \multicolumn{4}{|l|}{ Trypsin-chymotrypsin digestion } \\
\hline Maximal degradation (ODmax) & 0.17 & 0.21 & NS \\
\hline Maximal rate of digestion & 0.88 & 0.82 & $*$ \\
\hline \multicolumn{4}{|l|}{$(\Delta \mathrm{OD} / \mathrm{h})$} \\
\hline Half-life time (min) & 9 & 13 & NS \\
\hline In vivo & Veal, $30 \mathrm{~min}$ at $75^{\circ} \mathrm{C}$ & $\begin{array}{l}\text { Veal, } 30 \min \text { at } \\
\qquad 95^{\circ} \mathrm{C}\end{array}$ & \\
\hline True ileal digestibility, $\%$ & 95.6 & 95.3 & NS \\
\hline $\begin{array}{l}\text { Maximal rate of IAA appearance in } \\
\text { plasma }(\Delta[\text { IAA }] / \mathrm{min})\end{array}$ & 22.8 & 13.0 & $* *$ \\
\hline $\begin{array}{l}\text { Time of maximal plasma IAA } \\
\text { concentration ( } \mathrm{min})\end{array}$ & 165 & 290 & $*$ \\
\hline
\end{tabular}




\section{ACCEPTED MANUSCRIPT}

Table 3

\begin{tabular}{|c|c|c|c|c|}
\hline $\begin{array}{l}\text { Type of } \\
\text { study }\end{array}$ & $\begin{array}{l}\text { Polyphenols } \\
\text { studied }\end{array}$ & $\begin{array}{l}\text { Bioaccessibility/ Bioavailability } \\
(\%)\end{array}$ & Studied by & Reference \\
\hline In vitro & Apple pp, FC* & $55 \%$ mean bioaccessibility & $\begin{array}{l}\text { GI digestion and } \\
\text { dializability }\end{array}$ & (Bouayed et al., 2011) \\
\hline In vitro & $\begin{array}{l}\text { Apple } \\
\text { polyphenols, } \\
\text { HPLC }\end{array}$ & $\begin{array}{l}24.7 \% \text { overall dialiyzability, } \\
49.2 \% \text { overall bioaccessibility } \\
31-56 \% \text { intestinal recovery }(0.5- \\
21 \% \text { dialysis) for chlorogenic acids }\end{array}$ & $\begin{array}{l}\text { GI digestion and } \\
\text { dialyzability }\end{array}$ & (Bouayed et al., 2012) \\
\hline In vitro & Apple pp & $\begin{array}{l}\text { Procyanidins: } 55 \% \\
\text { Rutin: } 47 \% \\
\text { Phloridzin: } 45 \%\end{array}$ & $\begin{array}{l}\text { GI digestion and } \\
\text { bioaccessibility }\end{array}$ & (Tenore et al., 2013) \\
\hline In vitro & $\begin{array}{l}\text { Cashew apple } \\
\text { juice pp, FC }\end{array}$ & $39 \%$ overall bioaccessibility & $\begin{array}{l}\text { GI digestion and } \\
\text { bioaccessibility }\end{array}$ & (de Lima et al., 2014) \\
\hline In vitro & $\begin{array}{l}\text { Isoflavones from } \\
\text { bread }\end{array}$ & $\begin{array}{l}\text { Daidzein: } 59 \% \\
\text { Genistein: } 33 \% \\
\text { Daidzein-genistein ratio: } 1.8 \\
\text { Glycitein: } 75 \% \\
\text { Glucosides: mostly > }>00 \%\end{array}$ & $\begin{array}{l}\text { GI digestion and } \\
\text { bioaccessibility }\end{array}$ & (Walsh et al., 2003) \\
\hline In vitro & $\begin{array}{l}\text { Isoflavones from } \\
\text { pretzels }\end{array}$ & $\begin{array}{l}\text { Total isoflavones: } 78-85 \% \\
\text { Aglycons (genistein, daidzein, } \\
\text { glycitein): } 40-60 \%\end{array}$ & $\begin{array}{l}\text { GI digestion and } \\
\text { bioaccessibility }\end{array}$ & (Simmons et al., 2012) \\
\hline In vivo & $\begin{array}{l}\text { Apple pp in } \\
\text { ileostomists, }\end{array}$ & $\begin{array}{l}<5.3 \% \text { recovery for } 5- \\
\text { caffeoylquinic acid, } 4-\text { p- } \\
\text { coumaroylquinic acid, caffeic acid, } \\
\text { (-)-epicatechin, phloretin, quercetin }\end{array}$ & AUC in plasma (8h) & (Kahle et al., 2011) \\
\hline In vivo & $\begin{array}{l}\text { Apple smoothie } \\
\text { pp in ileostomists }\end{array}$ & $63 \%$ recovery overall & $\begin{array}{l}\text { Recovery in } \\
\text { ileostomist fluids }\end{array}$ & (Hagl et al., 2011) \\
\hline In vivo & Isoflavones & $\begin{array}{l}\text { Daidzein: } 29.5 \% \text { (low dose) } \\
\text { Geinstein: } 8.9 \% \text { (low dose) } \\
\text { Ratio daidzein: genistein: } 3.3\end{array}$ & $\begin{array}{l}\text { Faecal balance based } \\
\text { on stable isotope } \\
\text { administration }\end{array}$ & (Setchell et al., 2003) \\
\hline In vivo & $\begin{array}{l}\text { Isoflavones from } \\
\text { a soy-tomato } \\
\text { juice, healthy } \\
\text { subjects }\end{array}$ & $\begin{array}{l}49.3 \% \text { recovery (after cleaving of } \\
\text { glucorinides/sulfates) } \\
\text { Daidzein: } 70 \% \\
\text { Genistein: } 15 \% \\
\text { Daizein-genistein ratio: } 4.7 \\
\text { Glycitein: } 31 \%\end{array}$ & $\begin{array}{l}\text { Urinary excretion }(24 \\
\text { h pool) }\end{array}$ & (Bohn et al., 2013) \\
\hline
\end{tabular}




\section{ACCEPTED MANUSCRIPT}

Table 4

\begin{tabular}{lcc}
\hline $\begin{array}{l}\text { In vivo data / Digestion of test meals } \\
\text { in healthy volunteers }\end{array}$ & $\begin{array}{c}\text { Gastric lipolysis (\%) }^{a} \\
\begin{array}{l}\text { Liquid test meal (Carrière et al., } \\
\text { 1993) }\end{array}\end{array}$ & $\begin{array}{c}\text { Lipolysis (\%) at the angle of Treitz } \\
\text { (gastric }+ \text { duodenal lipolysis) }^{b}\end{array}$ \\
$\begin{array}{l}\text { Liquid test meal (Carrière et al., } \\
\text { 2001) }\end{array}$ & $10.0 \pm 1.0$ & nd \\
$\begin{array}{l}\text { Solid-Liquid test meal (Carrière et } \\
\text { al., 2001) }\end{array}$ & $9.3 \pm 6.3$ & $27.7 \pm 5.7$ \\
$\begin{array}{l}\text { Solid-Liquid test meal (Carrière et } \\
\text { al., 2005) }\end{array}$ & $7.3 \pm 5.9$ & $20.8 \pm 11.2$ \\
\hline
\end{tabular}

\begin{tabular}{lcc}
\hline $\begin{array}{l}\text { In vitro data / Digestion of test meals } \\
\text { and O/W emulsions }\end{array}$ & $\begin{array}{c}\text { Gastric lipolysis at } \\
t=30 \min (\%)\end{array}$ & $\begin{array}{c}\text { Gastric }+ \text { duodenal lipolysis at } \\
t=90 \min (\%)\end{array}$ \\
\hline $\begin{array}{l}\text { Liquid test meal (Carrière et al., } \\
\text { 2001) }\end{array}$ & $7.4 \pm 0.3$ & $72.3 \pm 0.9$ \\
$\begin{array}{l}\text { Solid-Liquid test meal (Carrière et } \\
\text { al., 2001) }\end{array}$ & $3.0 \pm 0.5$ & $53.7 \pm 0.3$ \\
$\begin{array}{l}\text { Rapeseed oil/lecithin emulsion (Vors } \\
\text { et al., 2012) }\end{array}$ & $9.5 \pm 2.0$ & $29.2 \pm 3.6$ \\
$\begin{array}{l}\text { Rapeseed oil/caseinate emulsion } \\
\text { (Vors et al., 2012) }\end{array}$ & $4.0 \pm 4.0$ & $42.0 \pm 2.3$ \\
$\begin{array}{l}\text { Milk fat olein/lecithin emulsion } \\
\text { (Vors et al., 2012) }\end{array}$ & $6.2 \pm 0.6$ & $20.9 \pm 2.6$ \\
$\begin{array}{l}\text { Milk fat olein/caseinate emulsion } \\
\text { (Vors et al., 2012) }\end{array}$ & $4.8 \pm 1.6$ & $50.3 \pm 2.0$ \\
$\begin{array}{l}\text { Flaxseed oil/lecithin emulsion } \\
\text { (Couedelo et al., 2015) }\end{array}$ & $16.3 \pm 0.8$ & $32.6 \pm 4.3$ \\
$\begin{array}{l}\text { Flaxseed oil/caseinate emulsion } \\
\text { (Couedelo et al., 2015) }\end{array}$ & $7.3 \pm 2.9$ & \\
\hline
\end{tabular}




\section{ACCEPTED MANUSCRIPT}

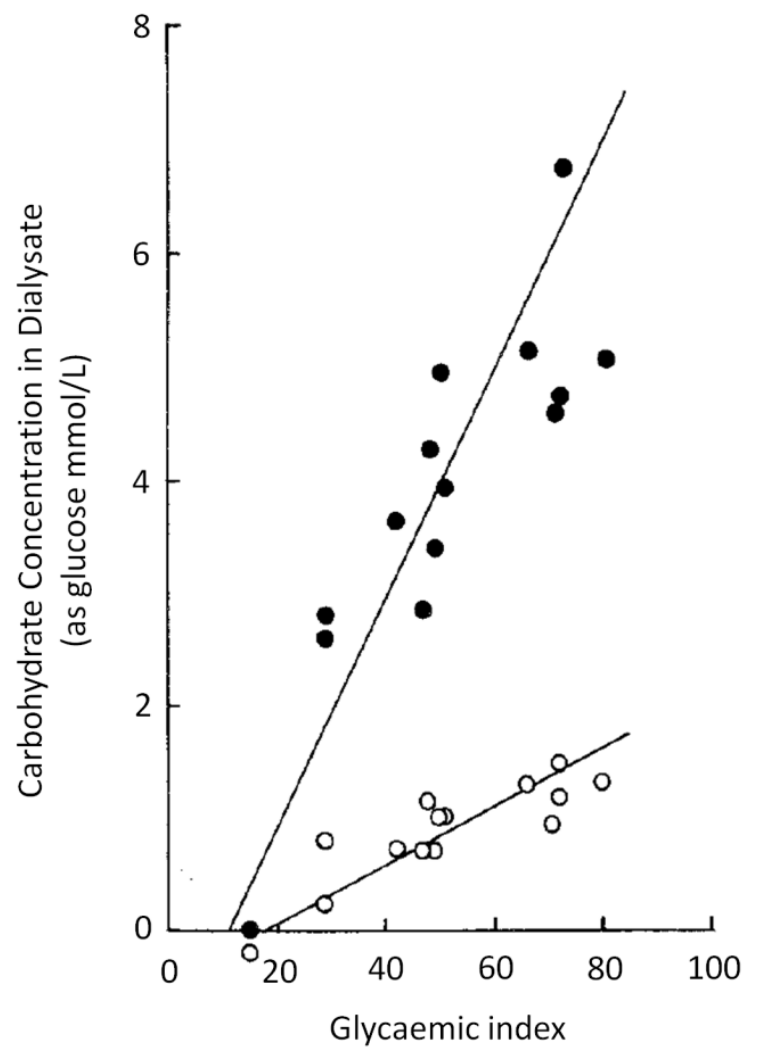

Figure 1 


\section{ACCEPTED MANUSCRIPT}

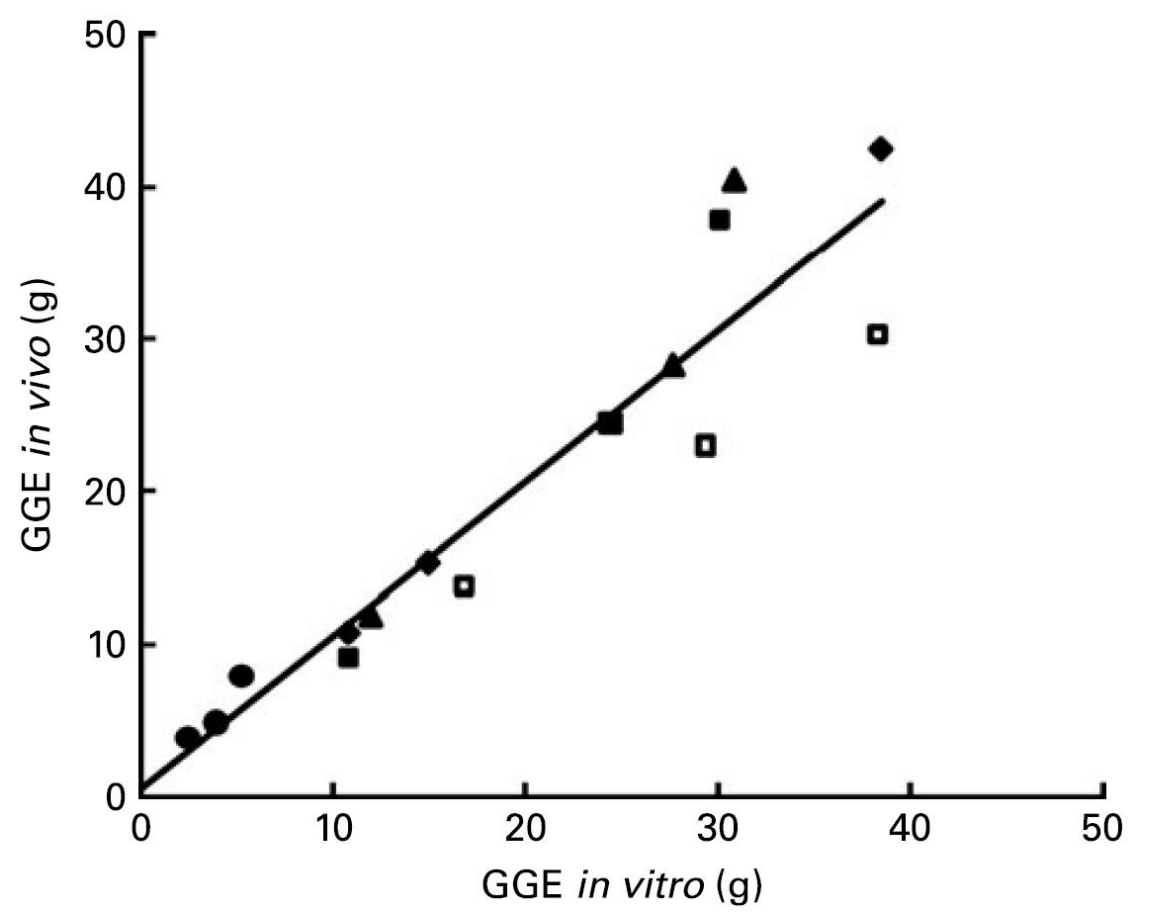

Figure 2 


\section{ACCEPTED MANUSCRIPT}

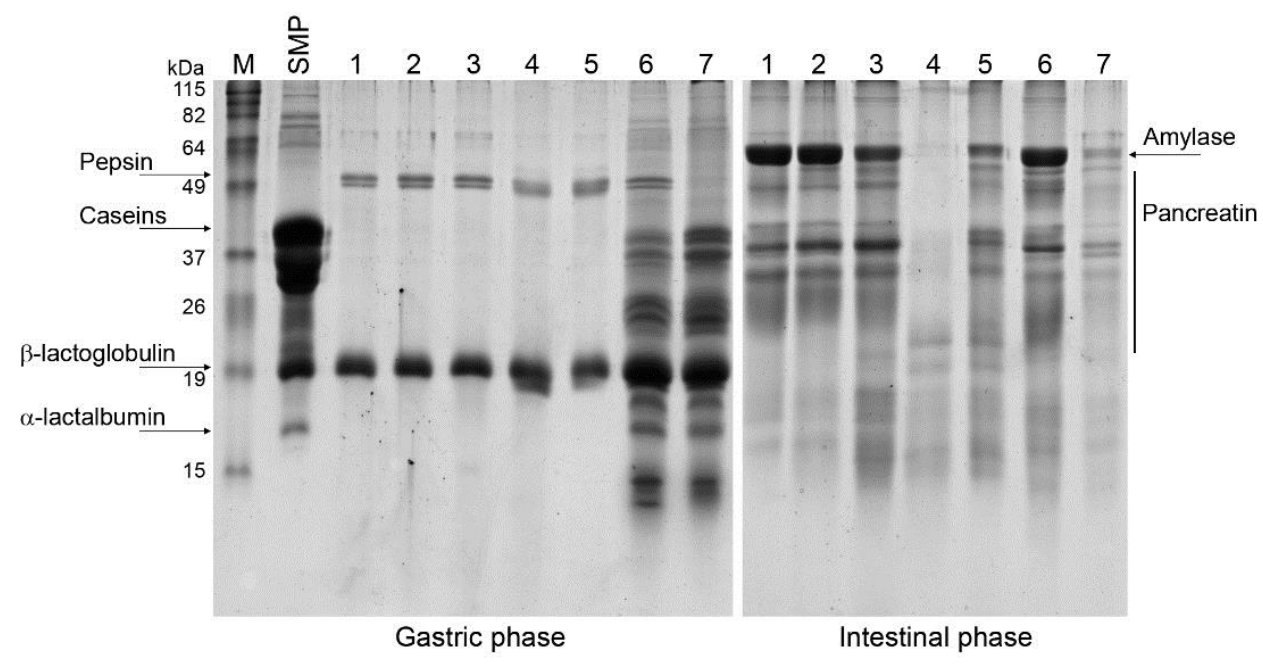

Figure 3 


\section{ACCEPTED MANUSCRIPT}

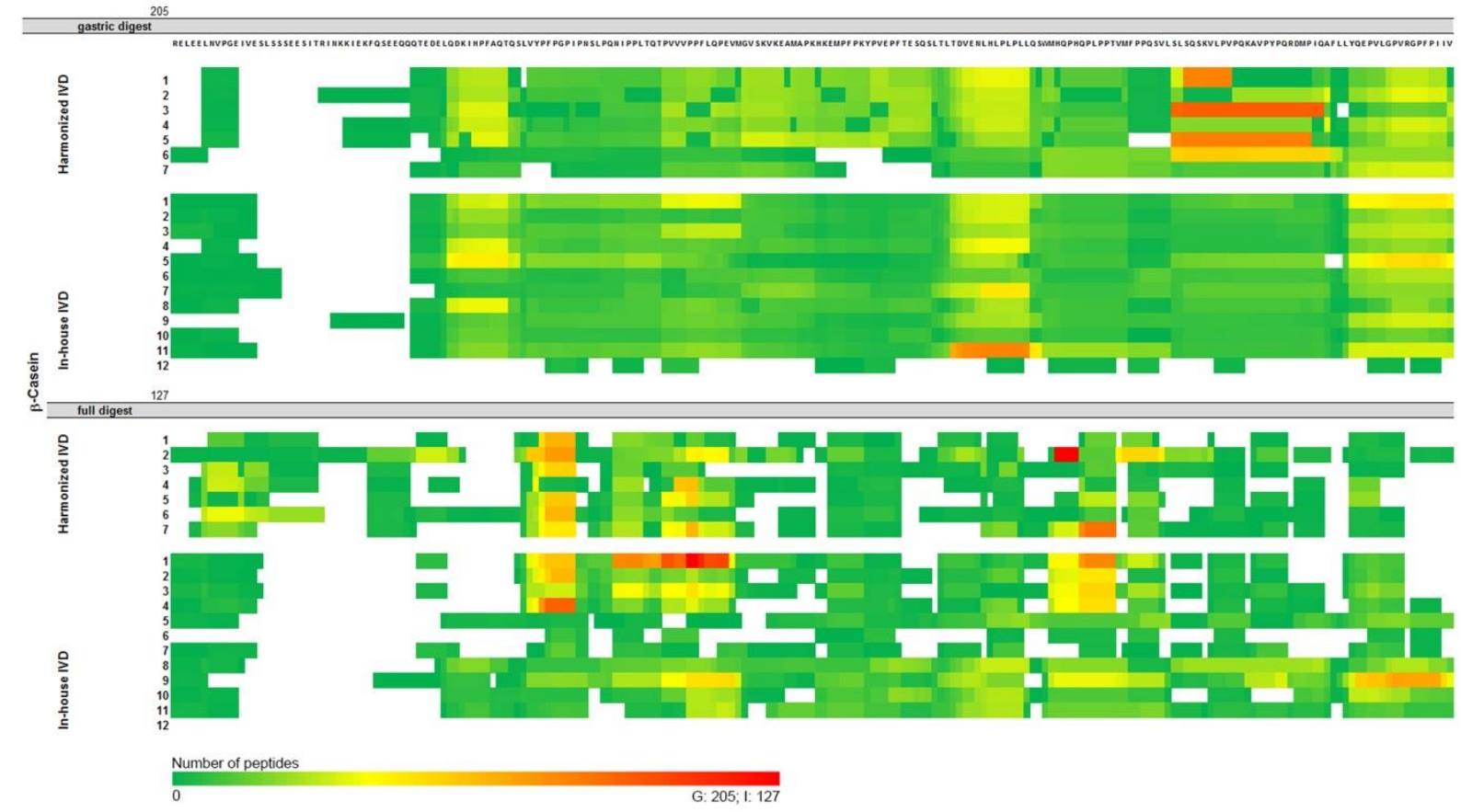

Figure 4 


\section{ACCEPTED MANUSCRIPT}

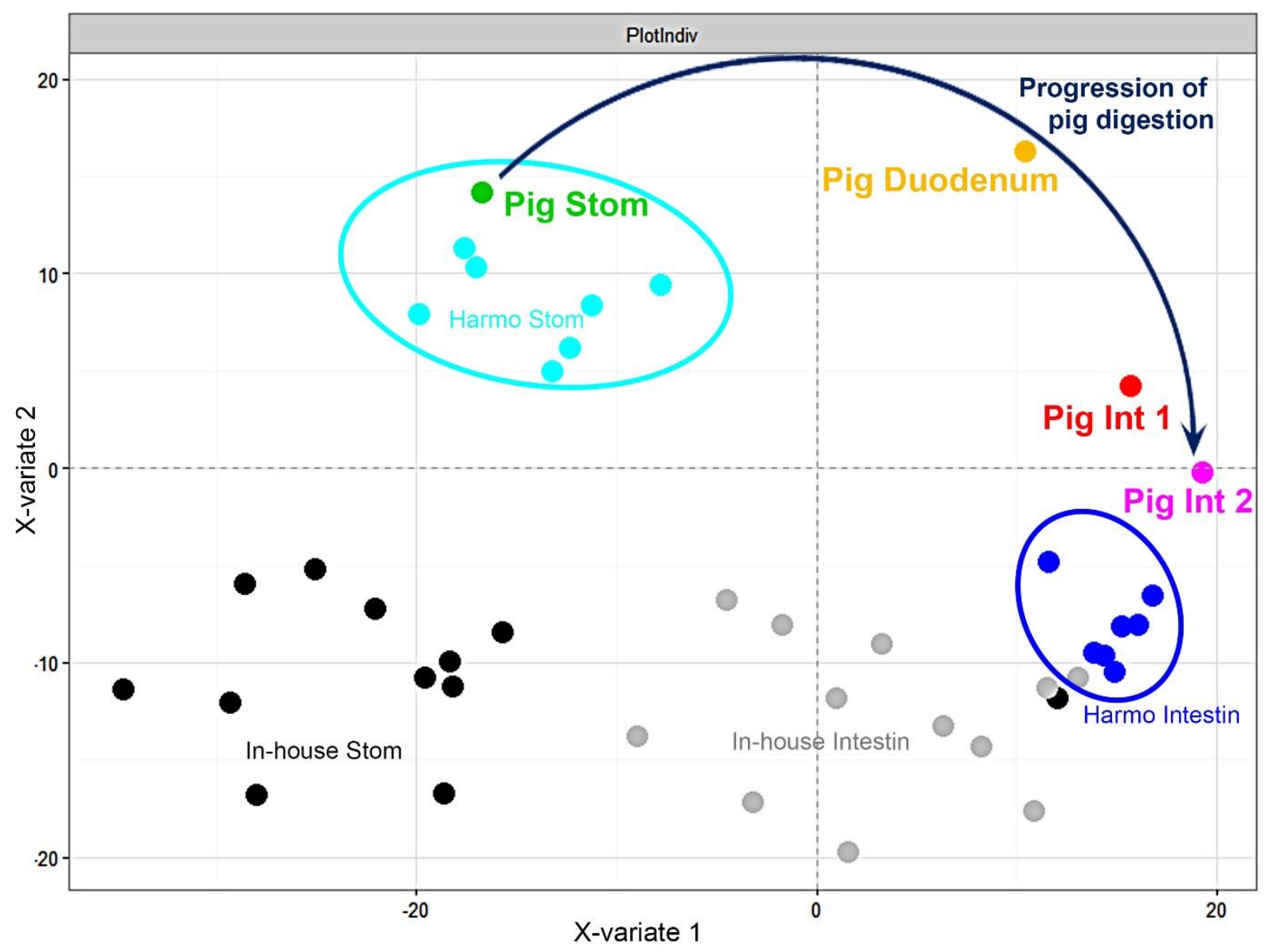

Figure 5 


\section{ACCEPTED MANUSCRIPT}

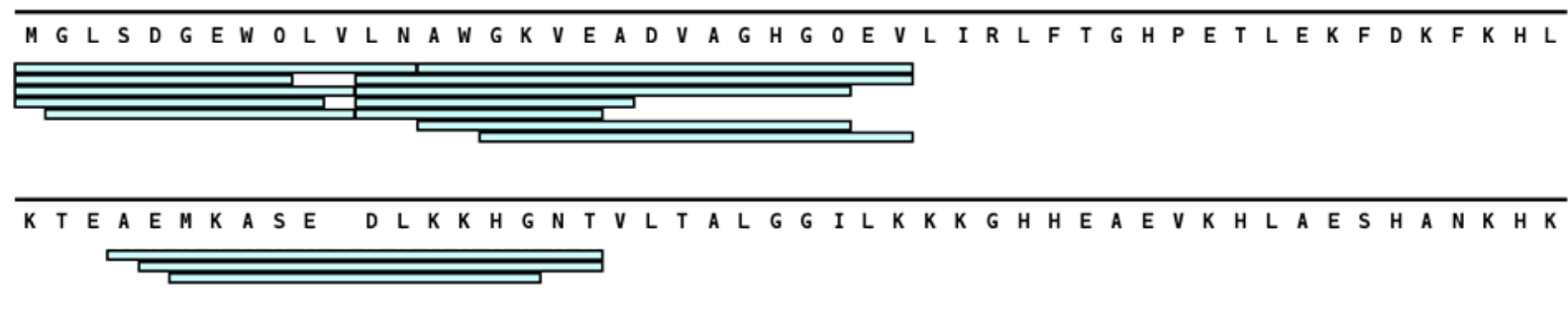

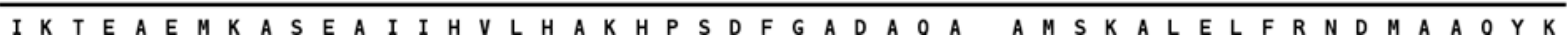

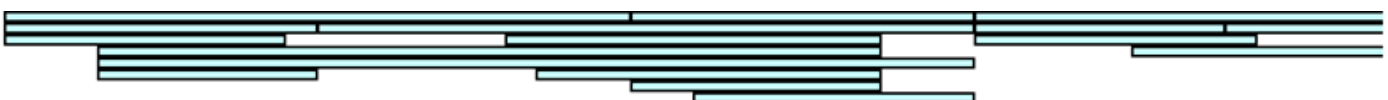

V L G F H G

$=$

in: ing: 92 of $156 \sim 59 \%$

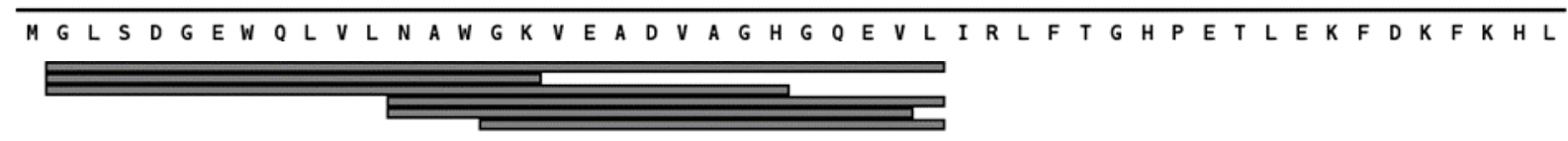

K T E A E M K A S E D D L K K H G N T V L T A L G G I L K K K G H H E A E V K H L A E S H A N K H K 

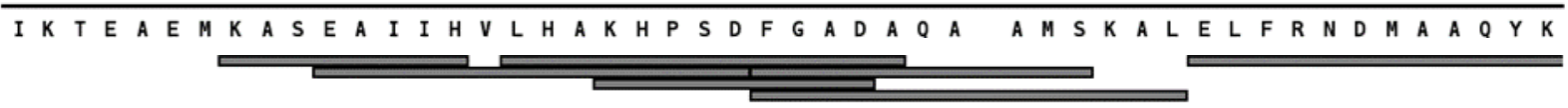

$\overline{V L G F H G}$

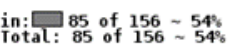

Figure 6 


\section{ACCEPTED MANUSCRIPT}

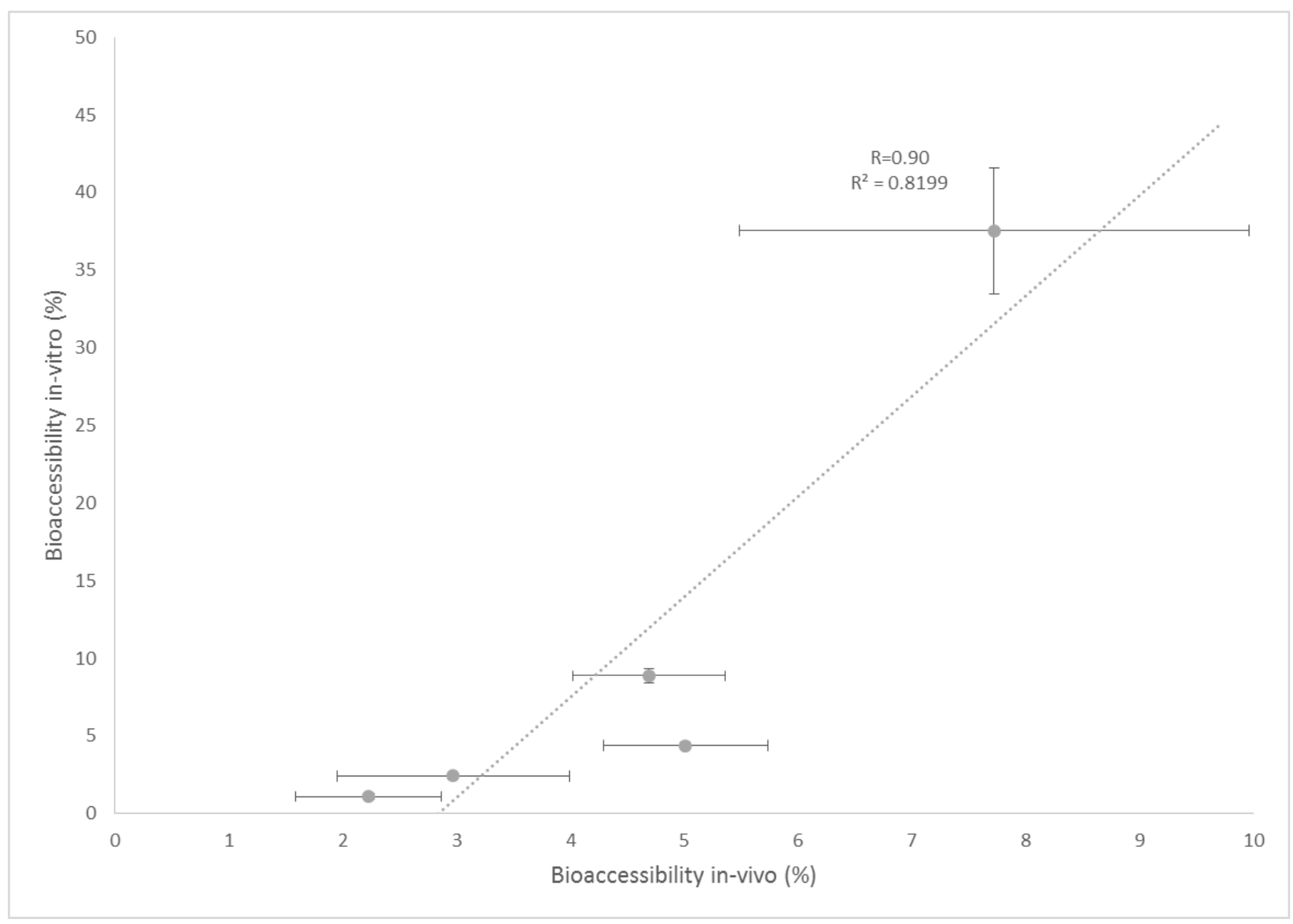

Figure 7 


\section{ACCEPTED MANUSCRIPT}

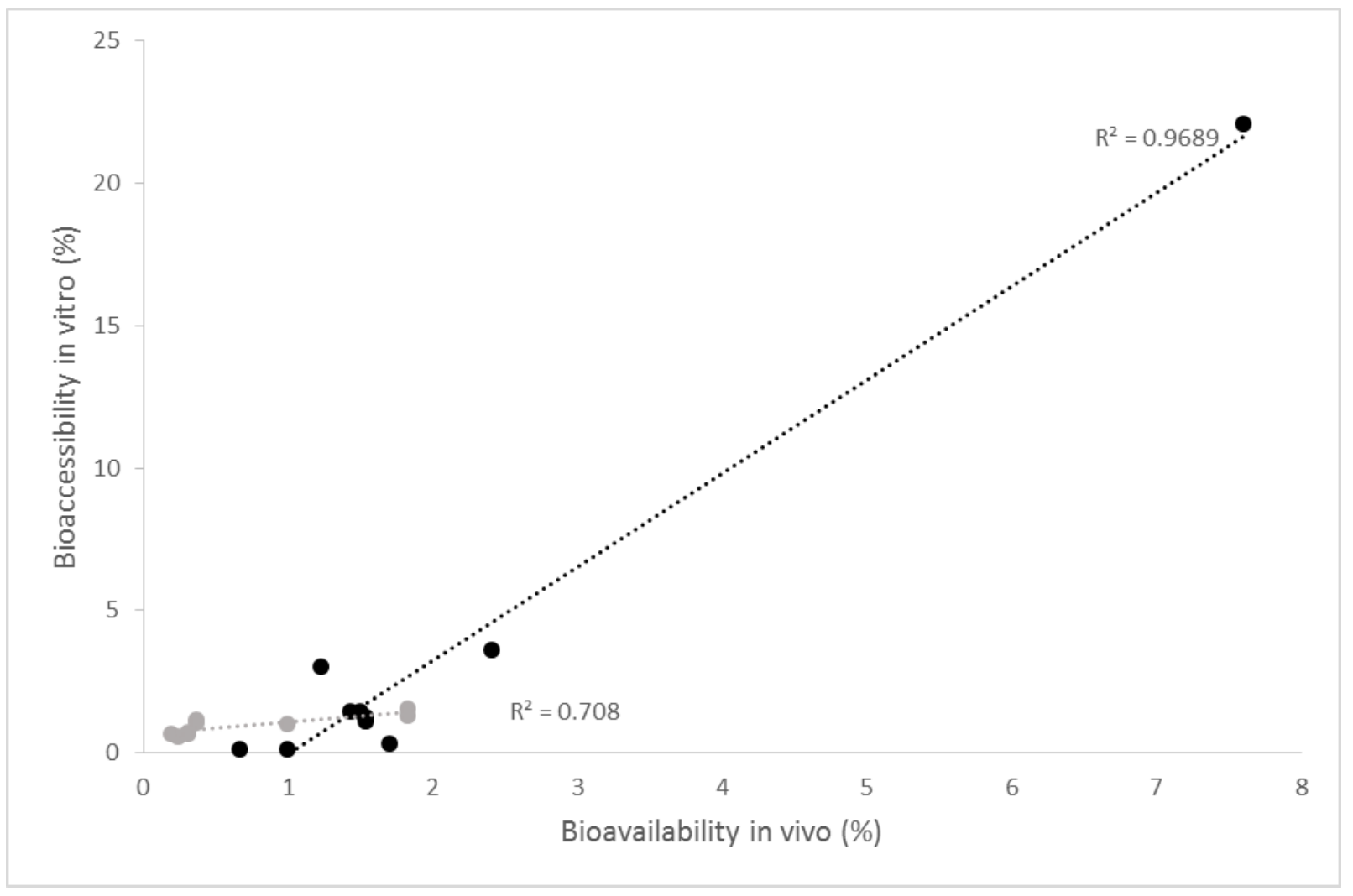

Figure 8 


\section{ACCEPTED MANUSCRIPT}

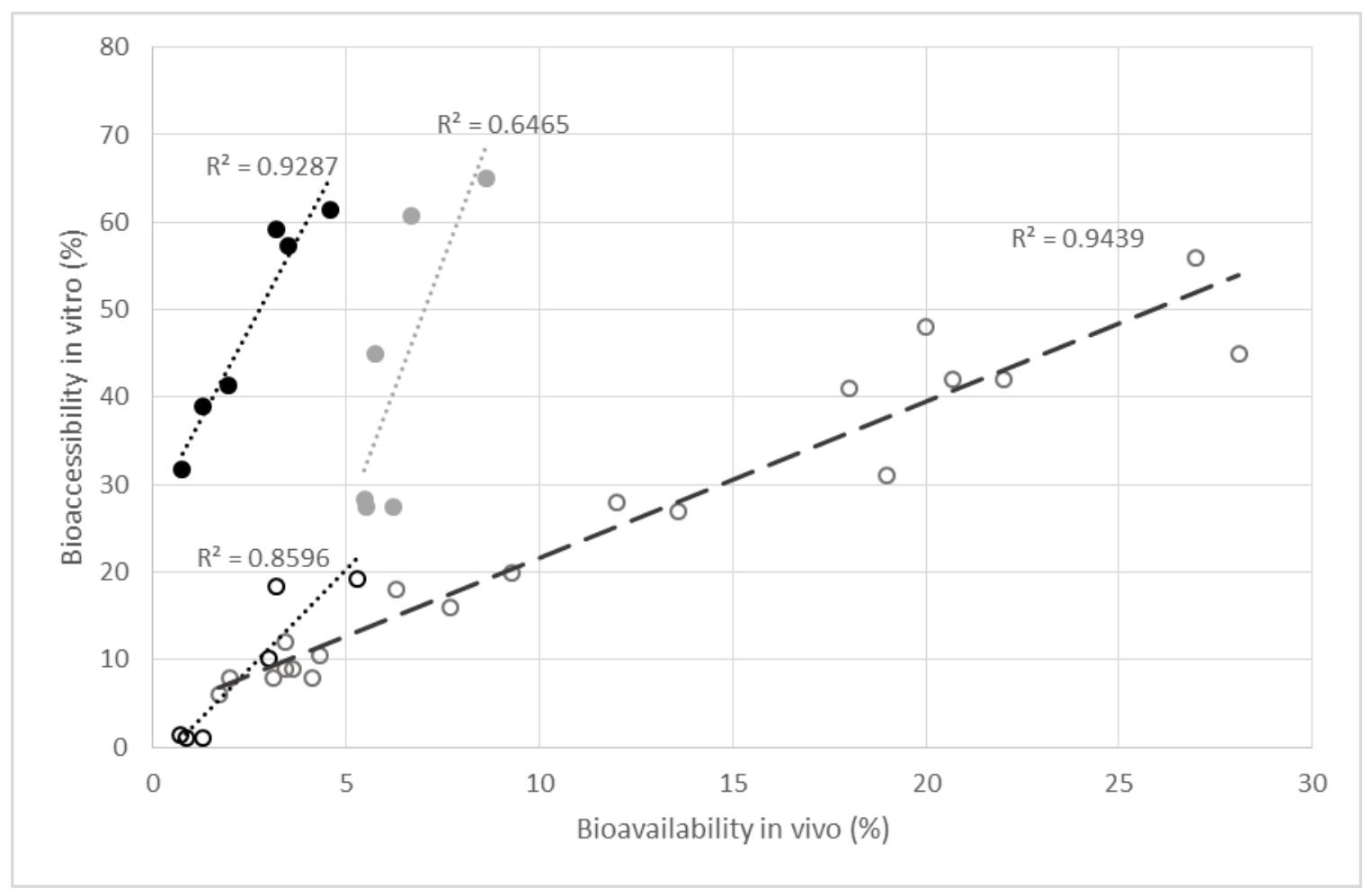

Figure 9 


\section{ACCEPTED MANUSCRIPT}
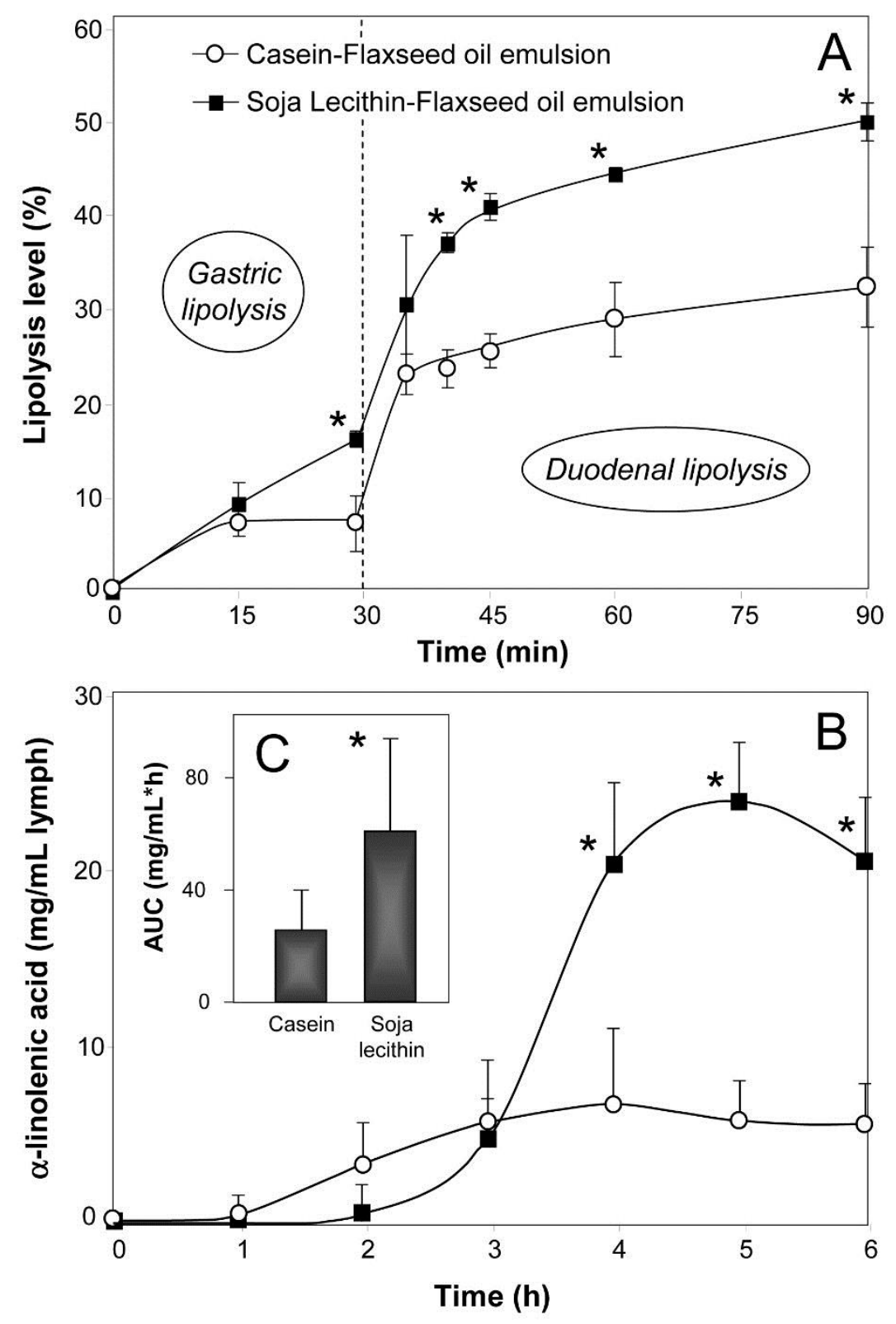

Figure 10 


\section{ACCEPTED MANUSCRIPT}
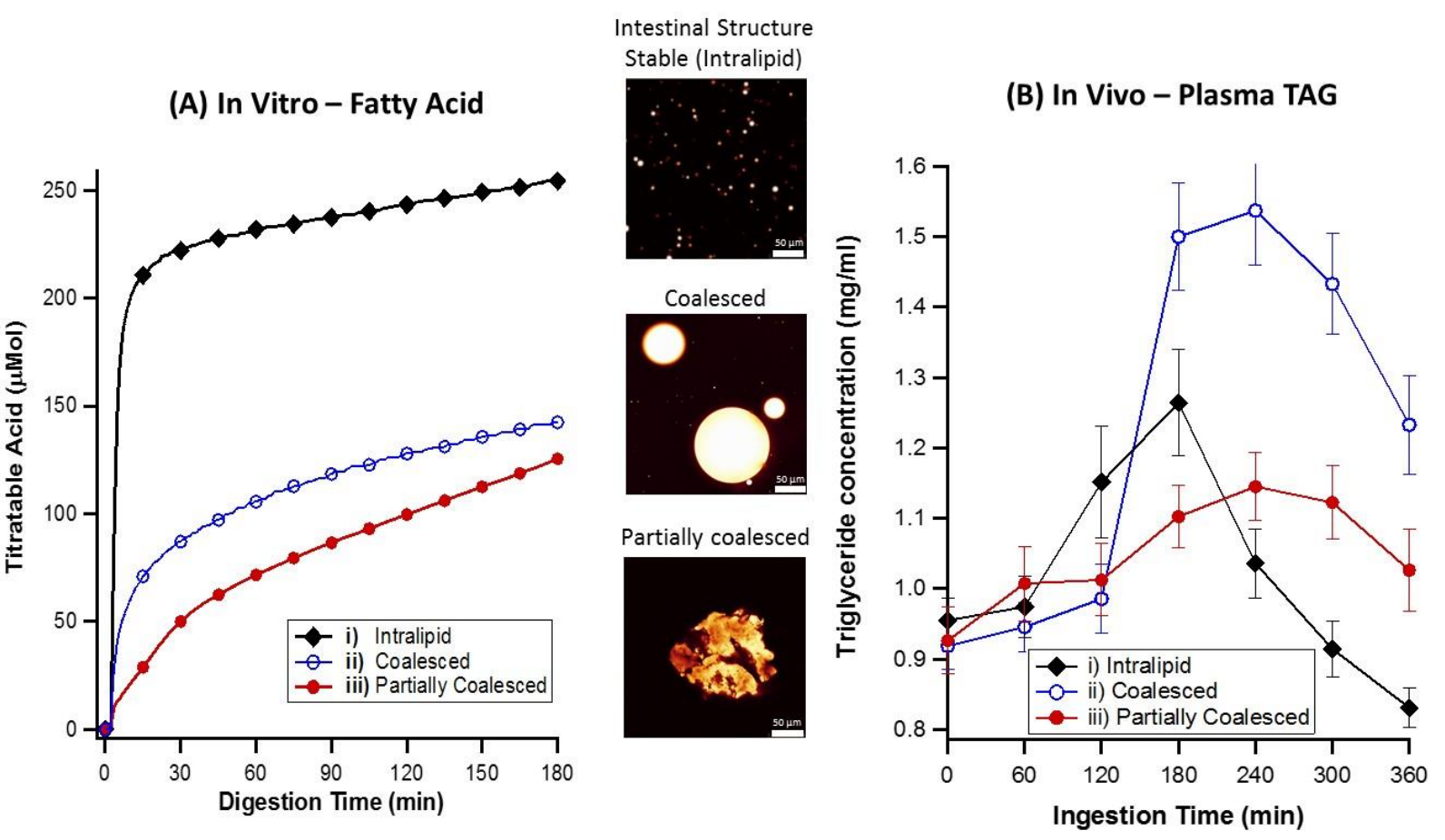

Figure 11 